Portland State University

PDXScholar

1981

\title{
An introduction to black and white lithography : two alternatives to the stone
}

Carolyn Brookhart

Portland State University

Follow this and additional works at: https://pdxscholar.library.pdx.edu/open_access_etds

Part of the Art Education Commons, Art Practice Commons, and the Printmaking Commons Let us know how access to this document benefits you.

Recommended Citation

Brookhart, Carolyn, "An introduction to black and white lithography : two alternatives to the stone" (1981). Dissertations and Theses. Paper 3148.

https://doi.org/10.15760/etd.3138

This Thesis is brought to you for free and open access. It has been accepted for inclusion in Dissertations and Theses by an authorized administrator of PDXScholar. Please contact us if we can make this document more accessible: pdxscholar@pdx.edu. 
AN ABSTRACT OF THE THESIS OF Carolyn Brookhart for the Master of Science in Teaching in Art presented November 12, 1981.

Title: An Introduction to Black and White Lithography: Two Alternatives to the Stone.

APPROVED BY MEMBERS OF THE THESIS COMMITTEE:

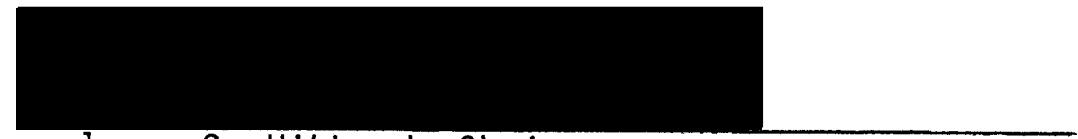

James S. Hibbard, Chairman
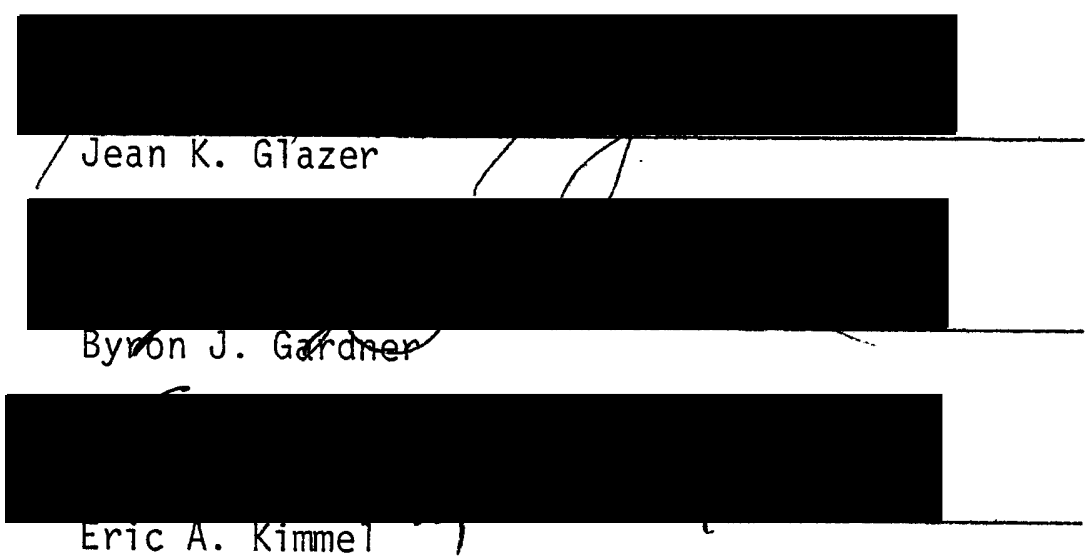

This thesis describes two lithographic techniques that may be used to introduce black and white lithography to beginning art students. Aluminum plate and paper lithography are two relatively low cost and safe lithographic methods suitable for schools with limited budgets and Timited space.

It is recommended that the instructor interested in teaching the two processes described in this thes is have some previous experience in 1 ithography. 
Equipment and supplies necessary for teaching plate lithography are described in Chapter IV. The step-by-step description of aluminum and paper plate lithography is contained in Chapters $V$ and VI and recommendations for teaching plate lithography are found in Chapter VII. Examples of student lithographs are included in this thesis. Although the range of drawing techniques possible in lithography is enormous, the techniques described in this thesis are 1 imited to those that are most suitable for beginning art students. School budgets and student safety were also taken into consideration when selecting the techniques and materials recommended in this thesis.

Aluminum plate and paper plate lithography provide beginning art students with an understanding of the essential characteristics of the Tithographic medium and an opportunity to successfulty complete an edition of their own prints. 
AN INTRODUCTION TO BLACK AND WHITE LITHOGRAPHY:

TWO ALTERNATIVES TO THE STONE

$$
\text { by }
$$

CAROLYN BROOKHART

\title{
A thesis submitted in partial fulfillment of the requirements for the degree of
}

\author{
MASTER OF SCIENCE \\ in \\ Teaching \\ in \\ Art
}

Portland State University

1981 
TO THE OFFICE OF GRADUATE STUDIES AND RESEARCH:

The members of the Committee approve the thesis of Carolyn Brookhart presented November 12, 1981.

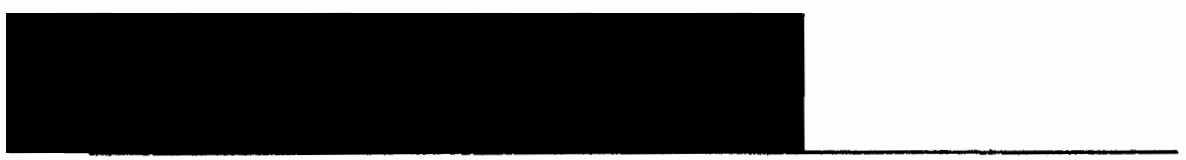

James S. Hibbard, Chairman
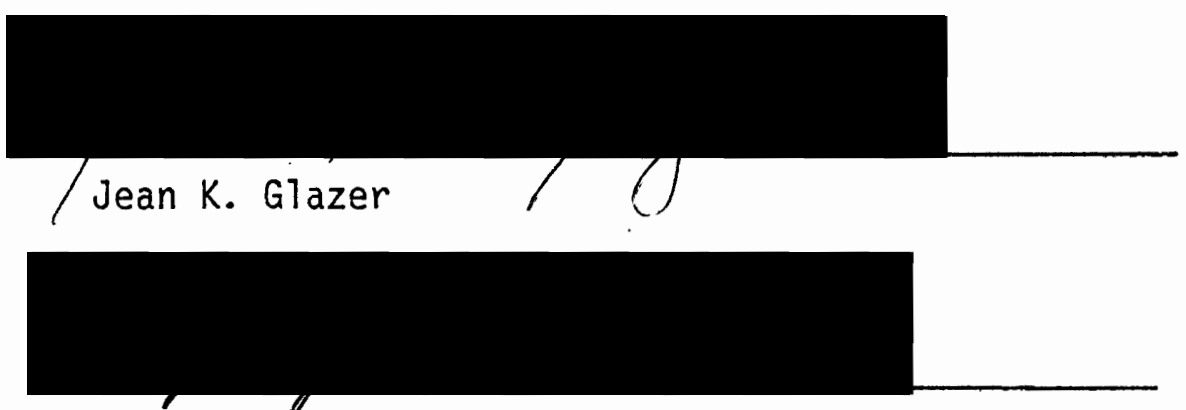

Byron J. Gardner

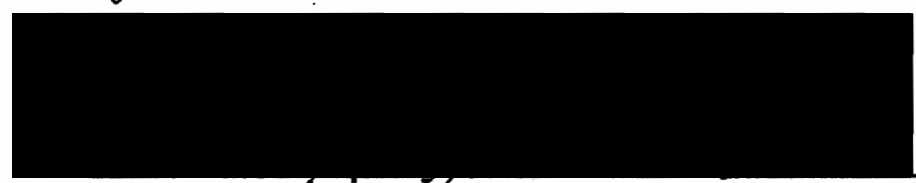

Eric A. Kimme11

APPROVED:

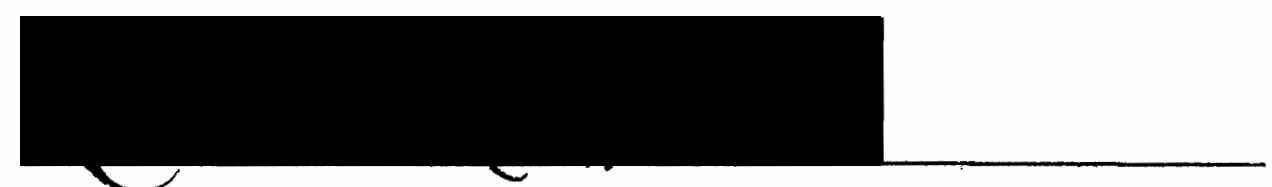

Leonard B. Kimbre11, Head, Department of Art

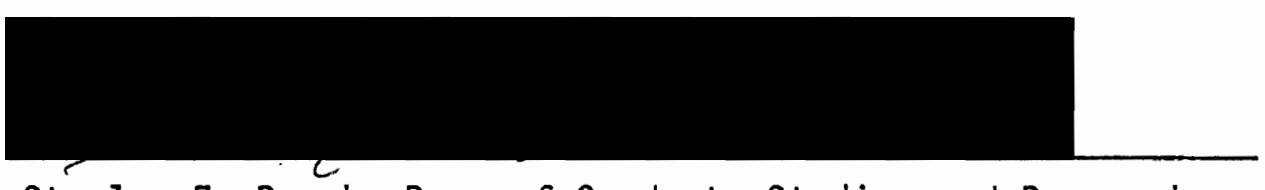

Stanley E. Rauch, Dean of Graduate Studies and Research 
TABLE OF CONTENTS

Page

LIST OF FIGURES . . . . . . . . . . . . . . . . v v CHAPTER

I INTRODUCTION . . . . . . . . . . . . . . 1

II SIGNIFICANCE OF LITHOGRAPHY IN THE SCHOOL ART PROGRAM • 3

II I BACKGROUND AND ADVANTAGES OF PLATE LITHOGRAPHY . . . . 5

Advantages of ATuminum Plates . . . . . . . 6

Paper plates.................. . . 7

IV EQUIPPING THE CLASSROOM FOR PLATE LITHOGRAPHY . . . . . 9

Equipment .............. 9

Classroom Design.............. 14

Safety................ . . 15

$\checkmark$ ALUMINUM PLATE LITHOGRAPHY . . . . . . . . . 18

Counteretching ............ . 18

Drawing on the Plate......... 20

Preparing the Aluminum Plate for Printing . . . . 25

Wash out............. . 31

Printing Base .............. . 32

Ro11 Up ............... . . . 33

The Second Etch . . . . . . . . . . 36

Printing ............. . . 37

Drying and Storing............ 40

Problems .................. 4 41 
CHAPTER

Page

VI PAPER PLATE LITHOGRAPHY . . . . . . . . . . . 43

Problems ................... 48

VII RECOMMENDATIONS AND CONCLUSIONS .......... 50

Recommendations for Teaching Plate Lithography . . 51

Conclusions ............. . . 53

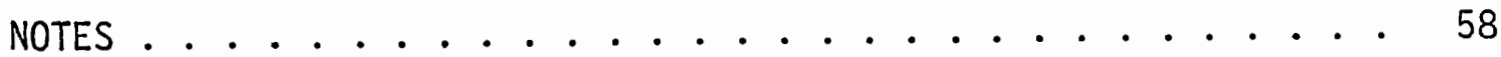

SOURCES CONSULTED ........................... 59

APPENDIX A ......................... 61

APPENDIX B ............................. 62

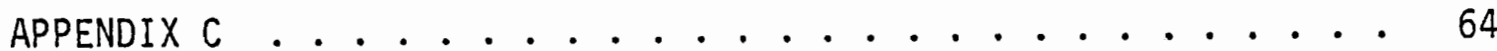




\section{LIST OF FIGURES}

\section{FIGURE}

1. Lithographic Press . . . . . . . . . . 10

2. Etching Press ............... 11

3. Lithographic Roller . . . . . . . . . . 12

4. Large Polyurethane Roller ............ 13

5. Polyurenthane Brayer ............. 19

6. Counteretching Plate............ 19

7. Blotting Plate Dry................ 19

8. Lithographic Drawing Materials ........... . 21

9. Protecting the Plate While Drawing......... 22

10. Rubbing Tusche on a Ceramic Dish . . . . . . . . 23

11. Solid Tusche mixed with Water . . . . . . . . 23

12. Etching Materials .............. 24

13. Dusting the Plate with Talc . . . . . . . . 26

14. Etching Chart for Aluminum Plates ........ . 27

15. Drawing Techniques Possible of Aluminum Plates . . . . . 28

16. Drawing Materials and Etch Stength for Figure 15 . . . 29

17. Etching the Plate ............ 30

18. Spot Etching the Plate ............ 31

19. Drying the Etch ............. 32

20. Washing out the Image ............ 32

21. The Image Washed Out . . . . . . . . . . . 32

22. Applying Asphaltum to the Plate ......... 33 
23. Removing the Gum with Water ............ . 34

24. Charging the Roller ............ 35

25. Wetting the Plate ............. 35

26. Inking the Plate.............. 35

27. Centering the Paper .............. 38

28. Plate Ready for Printing . . . . . . . . . . 38

29. Pulting the Print ............. 38

30. Plate Ready for Printing . . . . . . . . . . . 40

31. Operating the Etching Press ............ 40

32. Applying the Plate Solution ............ 46

33. Inking the Paper Plate.............. . 47

34. Fanning the Plate Dry ............. . . 47

35. Aluminum Plate Lithograph Printed on Rives Gray . . . . 54

36. Paper Plate Lithograph Printed on Domestic Etching . . . 55

37. Examples of Student Aluminum Plate Lithographs . . . . . 56

38. Examples of Student Paper Plate Lithographs . . . . . 57

39. Etching Chart for TAMPEM Etch ........... 63 
CHAPTER I

\section{INTRODUCTION}

The interest in original prints has been steadily expanding during the past thirty years. Today, many artists, collectors, museums, and schools are involved in the field of fine art printmaking. Printmaking workshops, print societies, and print exhibits are becoming more available to meet the needs of interested artists and collectors.

More and more colleges and art schools are adding printmaking to their curriculum. In fact, there are very few educational institutions, including the secondary schools, that do not offer some type of printmaking in their art program. ${ }^{1}$

Lithography is one of the four traditional printmaking processes available to the artist for producing multiple. works of art. . While lithography has experienced considerable success since its beginning in 1798 in both the commercial printing industry and as a fine art medium, the interest in fine art lithography has increased dramatically in the last two decades.

Much of the credit for this increased interest must go to the Tamarind Lithography Workshop. In 1960, the Tamarind Workshop was established in Los Angeles with a grant from the Ford Foundation to train skilled printers for collaboration with artists in the production of fine art lithography. Today, artists interested in lithography have the option to work with professional printers in enterprises such 
as Tamarind or to explore the technique in one of many independent workshops that exist across the country. Many colleges and art schools offer their students the opportunity to learn the art and craft of lithography in well equipped studios.

By adjusting the traditional 1ithographic materials, art departments with limited budgets and limited space can also introduce lithography successfully to beginning art students. This thesis describes two alternatives to traditional stone lithography suitable for school art programs. 


\section{CHAPTER II}

\section{SIGNIFICANCE OF LITHOGRAPHY IN THE SCHOOL ART PROGRAM}

Printmaking has long been considered an appropriate art activity for art students.

The merits of introducing printmaking to the very young are many. The experience of expressing themselves in another medium and developing their tactile sense is especially important. . . . The magic of the print process through the inking of a surface and production of an image that is not drawn or painted is an exciting experience for them.

The technical aspect of all printmaking processes is particularly appealing to the adolescent. Referring to printmaking in Creative and Mental Growth, Viktor Lowenfeld states that providing." . . adolescent youth with the opportunity of technical involvement without losing the initial desire for expression is one of the foremost tasks of the teacher in promoting adolescent art." ${ }^{3}$

Linoleum cuts, woodcuts, and screenprints are all printmaking forms that are commonly used in art classrooms. These media require little special equipment and as a result are easy and inexpensive to include in the art program. Unfortunately, etching and lithography are two processes often excluded from the art program because they are more complex, expensive, and often considered unsafe.

Both etching and lithography can be valuable additions to the art curriculum and they are particularly important to the art student's education because of their close relationship to drawing. Drawing, which is so important and fundamental to all art activity, may be 
discouraging to beginning students when they perceive their own work as unskilled and primitive. Beginner's drawings are often transformed and improved when they are converted into an etching or lithograph. Lowenfeld feels that both of these printmaking processes are important means of creating self-confidence in the adolescent art student. ${ }^{4}$

Lithography is even more directly related to drawing than is etching. "It lends itself to the creation of almost any type of image and its immediacy allows the artist to see the results of his labor instantaneously: The drawing is the image. ${ }^{5}$ The directness of 1 ithography and the fact that the drawing is produced with basically familiar materials make it so appealing to artists of all levels.

While the drawing of a lithographic image can be a simple procedure, the preparation of the drawing for printing and the printing process itself are quite complex and technical. It is during these stages that the student will learn the importance of craftsmanship. Careless handling during the etching and printing of a lithograph can easily destroy the work. In fact, sloppy work habits while drawing on the plate can also ruin the print. The student who approaches lithography in a careful, craftsmanlike manner will be able to successfully transform his own drawing into an edition of original prints.

By substituting certain materials for those traditionally used, 1 ithography can be successfuliy included as part of the school art program. Metal or paper lithographic plates make it possible for the beginning art student to explore the lithographic process without many of the problems associated with the traditional materials necessary for stone 1ithography. 
CHAPTER III

BACKGROUND AND ADVANTAGES OF PLATE LITHOGRAPHY

The Tithographic process was developed by Alois Senefelder in the 1790's. Unlike other printmaking techniques, 1ithography is a chemical process that essentially is based on the fact that water repels grease. Traditionally, a lithograph is produced by drawing on a flat, polished slab of limestone with a greasy substance. The drawing is chemically treated with a mixture of gum arabic and nitric acid, then inked and printed on a large press.

Although the lithographic stone has always been considered by most serious lithographers as the most sensitive of all surfaces on which to draw, the weight, high costs, and storage problems associated with stones caused many printers to seek other materials suitable for producing their lithographs. In fact, Senefelder himself, " . . experimented with iron, zinc, tin, lead and copper plates."6 Today lithographers use a variety of surfaces to produce their prints including stone, aluminum, zinc, multi-metal plates, and paper. Aluminum and zinc are two materials that are very suitable for lithography and have been used successfully for many years in commercial printing. These metal plates are used increasingly by artists in fine art lithography, often in conjunction with the stone.

Although both zinc and aluminum plates are popular with artists, aluminum plates are recommended for use in the general classroom. Because aluminum has almost completely replaced zinc in the commercial 
printing industry in the United States, it is more readity availabie and less expensive. It is also lighter in color, thus allowing the drawing on the plate to more closely resemble the finished print which will generally be printed on white paper.

\section{ADVANTAGES OF ALUMINUM PLATES}

There are several advantages in using aluminum plates rather than litho stones. A small stone, approximately $10^{\prime \prime} \times 12^{\prime \prime} \times 3^{\prime \prime}$ weighing twenty pounds, would cost at present, sixty dollars plus shipping. On a stone this size, an image no larger than $8^{\prime \prime} \times 10^{\prime \prime}$ can be produced. Care must be taken in handling and storing stones to avoid cracking or chippping the surface. In contrast, an aluminum plate $22^{\prime \prime} \times 28^{\prime \prime}$ and only .012" thick, costs about six dollars and is easy to transport and store.

Lithographic stones may be used repeatedly for many drawings by removing the old image with carborundum until a smooth, clean surface is prepared for the next print. However, graining a litho stone is physically demanding and requires special sink and plumbing arrangements. No special facilities are necessary for preparing aluminum plates. The grained aluminum plate comes from the supplier ready for the drawing.

When a lithographic drawing is complete, it must be chemically prepared for printing. Traditional stone lithography requires the use of nitric acid to etch the drawing but the etch described in Chapter $V$ for aluminum plates is simple to prepare and safe for beginning students to use. 
Those familiar with stone lithography know that a sturdy, specialized press is necessary in order to print a lithograph. Aluminum plates are easily printed on the standard litho press but may also be successfully printed on an etching press. For the teacher interested in providing students with experience in various printmaking techniques, the etching press can be a valuable investment. Etchings, collagraphs, woodcuts, linoleum cuts, and aluminum plate lithographs can all be printed, with only minor adjustment, on an etching press.

Teachers who feel that stone lithography is not feasible for beginning art students due to the costs, unwieldy size, harsh chemicals, and specialized equipment associated with the process, are able to introduce lithography by using aluminum plates. "For the small litho shop...or as part of the school curriculum, metal plates give the most versatile litho surface, both in terms of instruction and application...." 7

Those experienced with stone lithography, will find that drawing on aluminum plates does not offer the unique surface characteristic of stones, nor are the range of tones as great as those possible on stones. Nevertheless, aluminum plates offer the student an excellent introduction to the entire lithographic process. The student who learns to draw, process, and print an aluminum plate, can with very little adjustment, learn to print a stone.

\section{PAPER PLATES}

In 1958, Anthony Ensink, a Chicago chemist, developed a paper plate with a lithographic surface. These plates do not offer the range of drawing techniques possible on aluminum plates nor is the processing 
similiar to traditional lithography. Paper plates are, however, very inexpensive and the method is completely non-toxic. Furthermore, the etching and printing procedures are simplified and take less time than stone or aluminum plate lithography. For this reason, particularly, paper plates may be ideal for the art class that is limited to one fifty-five minute period each day. Paper plate lithographs may be printed on either a litho press or an etching press.

Suggestions for equipping the general art classroom for plate Tithography are offered in Chapter IV and the step-by-step process of aluminum plate and paper plate lithography from drawing through printing is described in Chapter V and VI. 


\section{CHAPTER IV}

\section{EQUIPPING THE CLASSROOM FOR PLATE LITHOGRAPHY}

In preparing a general art classroom for the production of plate lithography, several factors must be considered. Specific pieces of equipment must be secured, an efficient arrangement should be provided for etching and printing the plates, and certain measures must be taken to insure the safety of students.

\section{EQUUIPMENT}

\section{The Printing Press}

The major piece of equipment and the single largest investment will be the printing press. Both aluminum plate and paper plate lithographs may be printed on either the traditional litho press or on an etching press. In addition to cost, both the weight of the press and the amount of space needed to operate it must be taken into consideration.

Although they are easily adapted for use with plates, lithographic presses are designed primarily for printing stones. They must be sturdily constructed to support the weight of stones so they are generally heavier and more expensive than etching presses. Etching presses are produced in a wider variety of sizes, models, and prices than lithographic presses and are also available in table models that allow then to be stored with relative ease when not in use. 
Many press companies manufacture both types of presses and will respond to inquiries with up-to-date information on models and prices. For example, the Charles Brand Machinery Company, manufacturer of a complete line of quality litho and etching presses, offers five different models of lithographic presses ranging in weight from 1800 to 3600 pounds, and in price from $\$ 4310.00$ to $\$ 7845.00$. The same company sells twelve models of etching presses in both table and floor models ranging in weight from 139 pounds to 2459 pounds and in price from $\$ 530.00$ to $\$ 5640.00$

The Lithographic Press. Although lithographic presses may vary slightly depending on the manufacturer, the basic design is essentially the same (Figure 1). In addition to the press itself, it will be necessary to purchase scraper bars in various sizes and several tympans. The function of these items and the operation of the 1itho press are described in Chapter $V$. Manufacturers also provide complete information on the assembly, operation, and maintenance of their particular press.

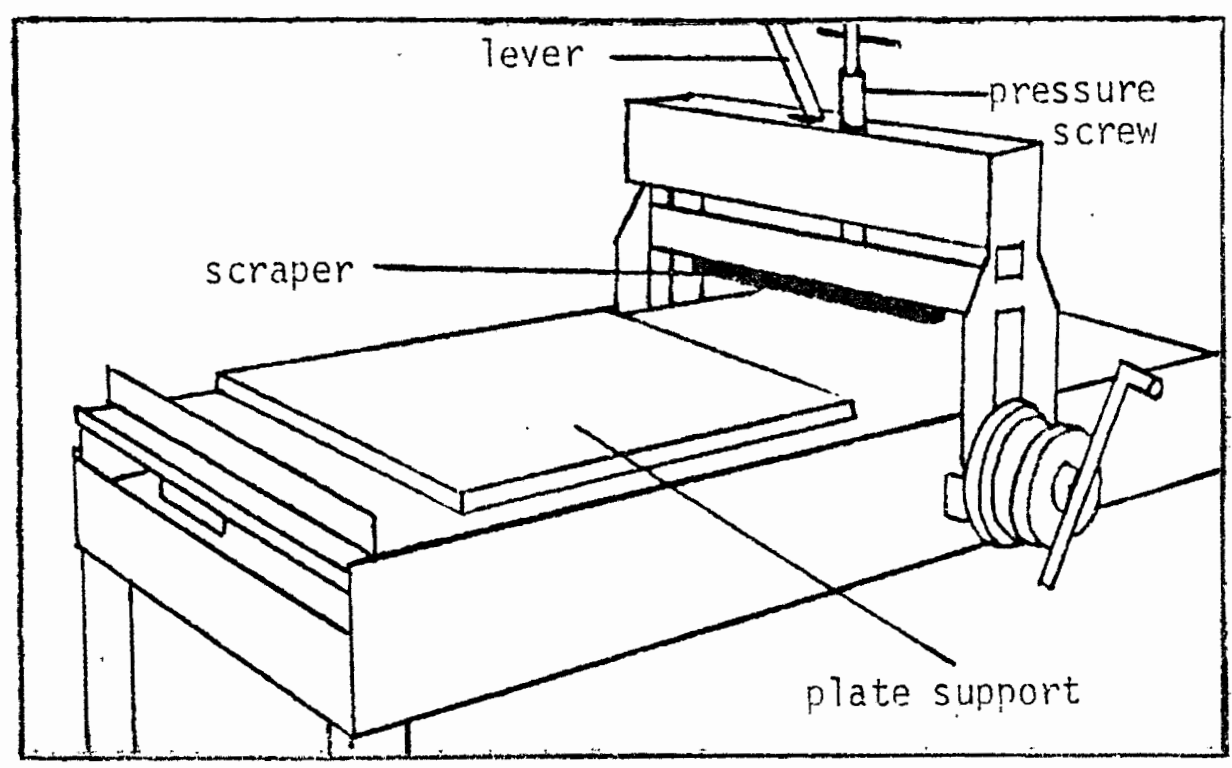

Fig. 1. Lithographic press 
Since litho presses are designed for stones at least two inches' thick, it will be necessary to provide a means of elevating the plate so that it will make contact with the scraper. An inexpensive plate support may be made with particleboard. It is important that the plate rest on a smooth surface so the particleboard should be covered with a material such as formica or masonite.

The Etching Press. Figure 2 illustrates a typical etching press. The operation of the etching press when printing plate lithographs is described in Chapter $V$. Some etching presses, including the one illustrated in Figure 2, are equipped with pressure indicator guages. These guages, while not essential, are very helpful when the etching press will be used for a variety of printmaking techniques.

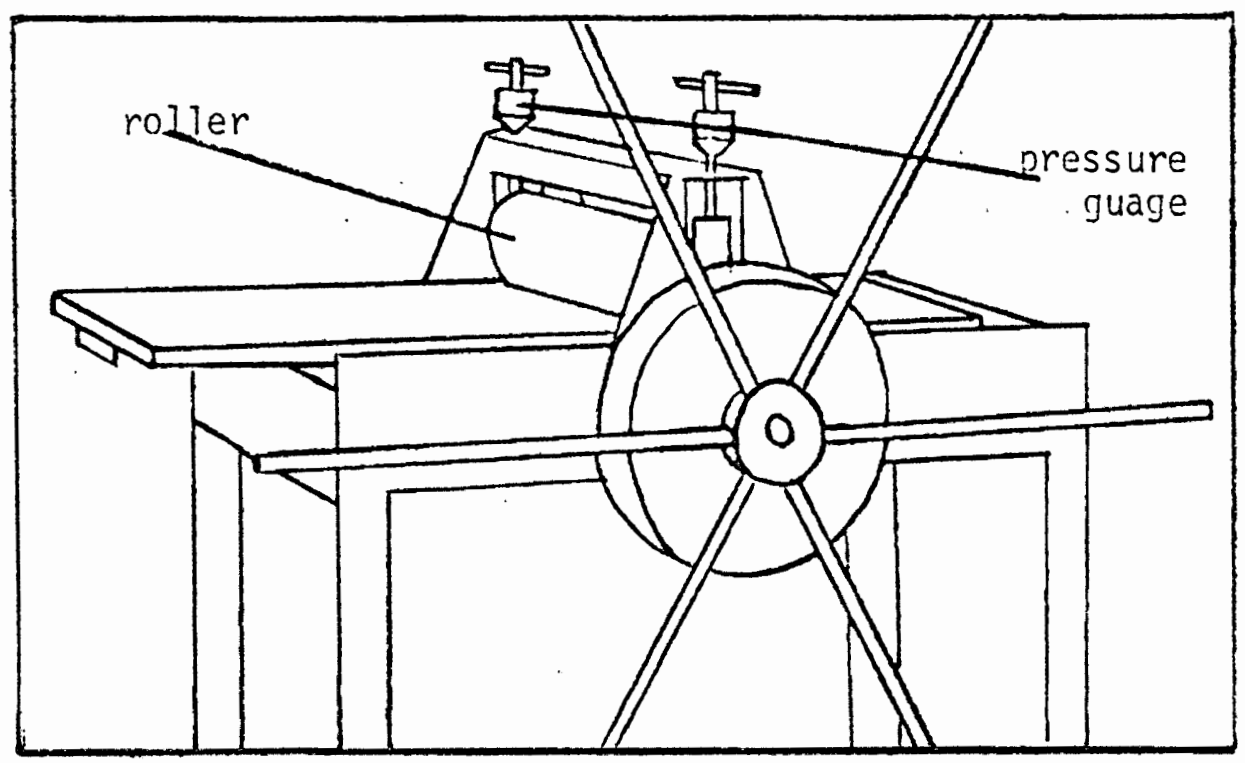

Fig. 2. Etching press

Two or three felt blankets are generally used when printing etchings or collagraphs. These blankets must be purchased in addition to the press and are available from the press manufacturer or from general 
printmaking suppliers. Blankets range in thickness from $1 / 16^{\prime \prime}$ to $1 / 4^{\prime \prime}$ with the thickest being the most expensive. When printing plate lithographs on the etching press, only one or two of the thin blankets is necessary. It is possible to substitute foam rubber, inexpensive felt, or even several blotters for the blankets when printing litho plates since they do not require the same amount of cushion necessary for printing etching.

\section{Rollers}

Traditional 1ithographic rollers are made with a wooden core and covered with leather (Figure 3 ). These are expensive rollers that are used only for lithography and each roller may only be used for one color of ink. If a lithographic leather roller is available, it may be used on aluminum plates with excellent results. The leather roller is not recommended for use with paper plate lithographs.

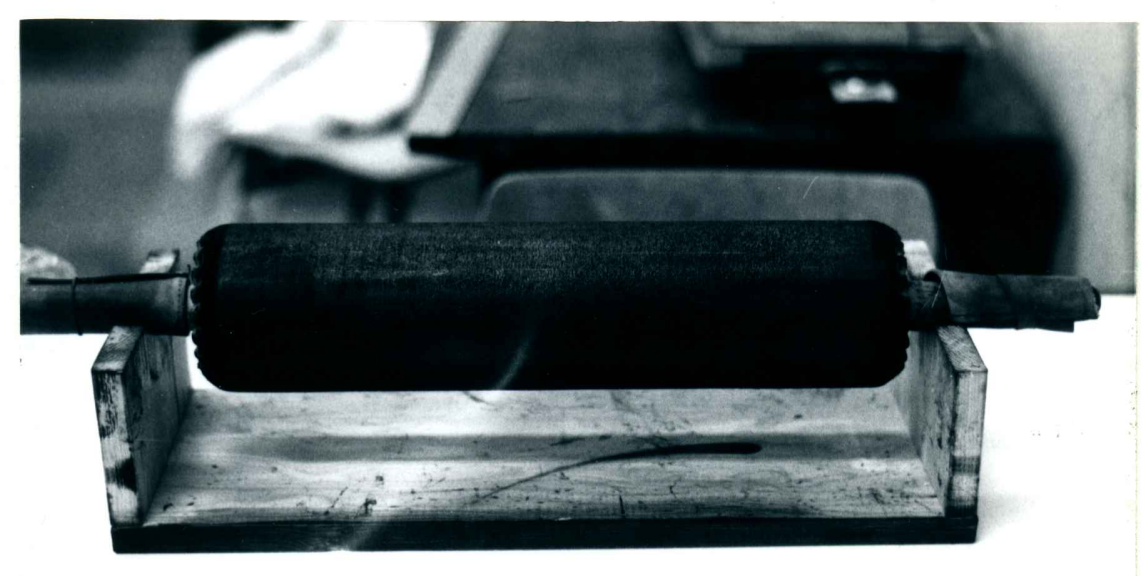

Fig. 3. Lithographic roller 
In a school situation, gelatin, rubber, or polyurethane rollers are much less expensive and may be used for a variety of printmaking techiques other than lithography. They are easily cleaned and may be used with different colors of ink. Large lithographic plates are easier to ink with a larger roller such as the one illustrated in Figure 4, but smaller rollers, known as brayers, may be used on any plate and they are considerably less expensive (Figure 5).

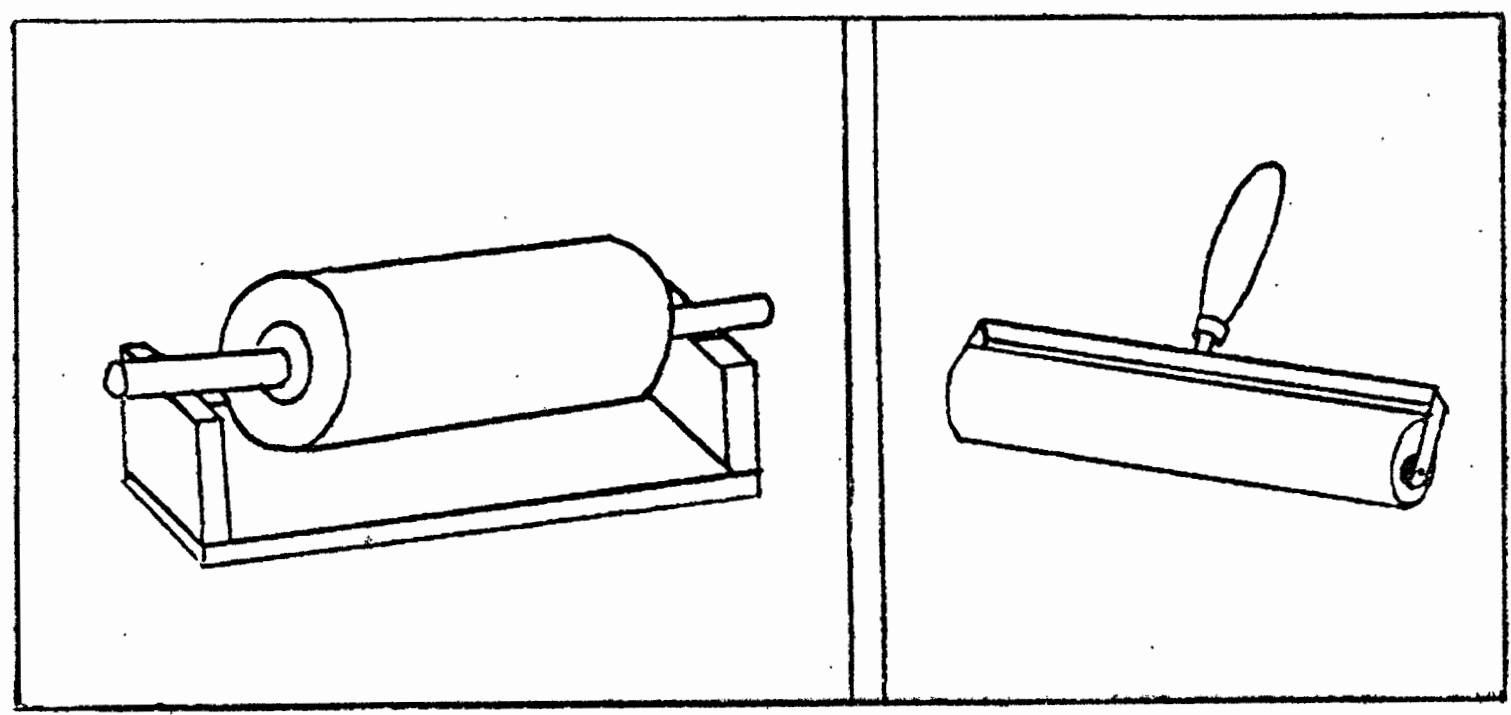

Fig. 4. Large polyurethane roller Fig. 5. Polyurethane brayer

\section{Paper}

Lithographic paper should be soft enough to readily accept the ink but hard enough to hold together without tearing when run through a press. Aithough an impression can be made on almost any paper, the best prints are obtained from good quality rag paper such as Rives BFK or Arches Cover. Unfortunately, the cost of these imported papers is probably excessive for many school budgets. A good, al1-purpose paper 
for beginning students and suitable for many printmaking processes is Domestic Etching. This is a $60 \% \mathrm{rag}$, machine made paper available at most art suppliers and the cost is approximately one third that of imported rag paper.

Inexpensive papers such as newsprint or bond are satisfactory for proofing but not for the finished print and colored papers that are not lightfast should be avoided.

\section{Miscellaneous Equipment}

In addition to the equipment described above and the specific supplies needed for drawing and processing the plates described in Chapters V and VI, certain materials will be needed for clean up. An abundant supply of clean rags is necessary not only for cleaning rollers, ink slabs, and work areas, but for etching and printing as we11. Inexpensive mineral spirits or paint thinner is used for all cleaning procedures and teachers may wish to purchase a supply of rubber gloves for students.

Appendix A contains a list of suppliers for all necessary lithographic equipment including presses, paper, chemicals, and drawina materials.

\section{CLASSROOM DESIGN}

No special facilities are needed for storage of aluminum or paper plates other than that they be kept free from contamination from grease, dirt, and moisture. Because plates are lightweight and portable, drawing on the plates may be done almost anywhere. In fact, students may easily take their plates home to work on the drawing. 
The inking and printing area should be arranged in such a fashion that etching, inking, and printing may proceed in an efficient manner. A cramped or poorly arranged working area can lead to unnecessary frustration during printing. A table or counter used for preparing and inking the plates should be situated adjacent to the press. Sufficient space must be provided for the press bed to move back and forth and ideally the press should be situated in such a way that access is possible from alt sides.

Drying racks or lines should be located in areas where finished prints may remain undisturbed until they are dry.

\section{SAFETY}

Handling Chemicals and Solvents

A11 chemicals used in paper plate lithography are safe and nontoxic and no special precautions are necessary when handling them. The etch recommended in Chapter $V$ for aluminum plate lithography is also relatively mild and safe for a school setting. Other etches described in Appendix $B$ and the Tacquer printing base procedure described in Appendix $C$ require greater care in handling and this should be considered when determining feasibility for classroom use.

The counteretch solutions for aluminum plates come from the supplier in concentrate form. It is assumed that it will be properly diluted by the teacher and only the diluted mixture available to the students. Nevertheless, some students with sensitive skin may find that certain brands cause irritation even after dilution, so rubber gloves may be worn. 
Since all lithography is based on the antipathy of grease and water, only oil based inks can be used for printing. Consequently, it will be necessary to use a solvent such as paint thinner for cleaning tools and work areas. The wash out procedure in aluminum plate 1 ithography requires the use of either turpentine or lithotine. Lithotine is a substitute for turpentine developed for use in lithography to reduce the skin problems sometimes connected with prolonged contact with turpentine. It is more expensive than turpentine and is available from printmaking suppliers. Students may wish to wear rubber gloves when handling these solvents either because of sensitive skin or for cosmetic reasons.

Solvents should never be used to clean ink from the skin. Creams designed for this purpose are preferred and are readity available from printmaking suppliers or automotive supply firms.

Fumes

Adequate ventilation must be provided in the classroom when using solvents such as turpentine, lithotine, or paint thinner. Generally, exposure to airborn concentrations of these solvents is for such a short duration that an open window may be a sufficient form of ventilation, however local exhaust systems or total room air exchange systems are preferred. Placement of the press and inking table should take into account the ventilation available in the classroom.

Solvents should be kept in clearly marked containers of metal or plastic, never glass. Lids should remain on when not in use to prevent unncessary evaporation of fumes into the air. 
The solvents used in plate lithography have high flash points and are relatively safe to use, nevertheless, common sense dictates that no solvent should be used near an open flame. Rags and paper soaked with solvents should be disposed of in safety disposal containers. These are metal containers equipped with self-closing 1 ids that will contain a fire should one begin and also prevent the constant evaporation of solvents into the atmosphere. 


\section{CHAPTER V}

\section{ALUMINUM PLATE LITHOGRAPHY}

Commercially grained aluminum plates are available from printmaking suppliers and often from retail art stores as well. The plates most commonly used for fine art 1ithography are .012" thick and come in sizes ranging from $20^{\prime \prime} \times 26^{\prime \prime}$ to $38^{\prime \prime} \times 50^{\prime \prime}$. They are light gray in color.

The plates are easily cut to size with a scissors, a paper cutter, or by scoring with a knife and straight-edge and breaking into smaller sizes. The corners should be rounded with a scissors and any sharp edges filed smooth. Plates are cut approximately two inches larger on all sides than the drawing. Margins of this size greatly facilitate the inking and printing procedures.

\section{COUNTERETCHING}

After the plate is cut to size, it must be counteretched to remove any oxides that may have formed on the surface. These oxides, if allowed to remain, will cause the drawing to lift from the plate during printing.

Commercially prepared counteretch solutions are available from lithography suppliers and are easy to prepare and reliable. Counteretch solutions usually come in concentrate form and are diluted with water according to the directions on the container. 
The plate is placed in a tray or on newspapers and a smal1 amount of counteretch solution is poured on the plate. The solution is rubbed over the surface of the plate for several minutes with a clean cloth (Figure 6). The surface of the plate is quickly rinsed with water and blotted dry (Figure 7). When the plate is dry, it is advisable to buff the surface of the plate with a dry, clean cloth to remove any particles of lint.

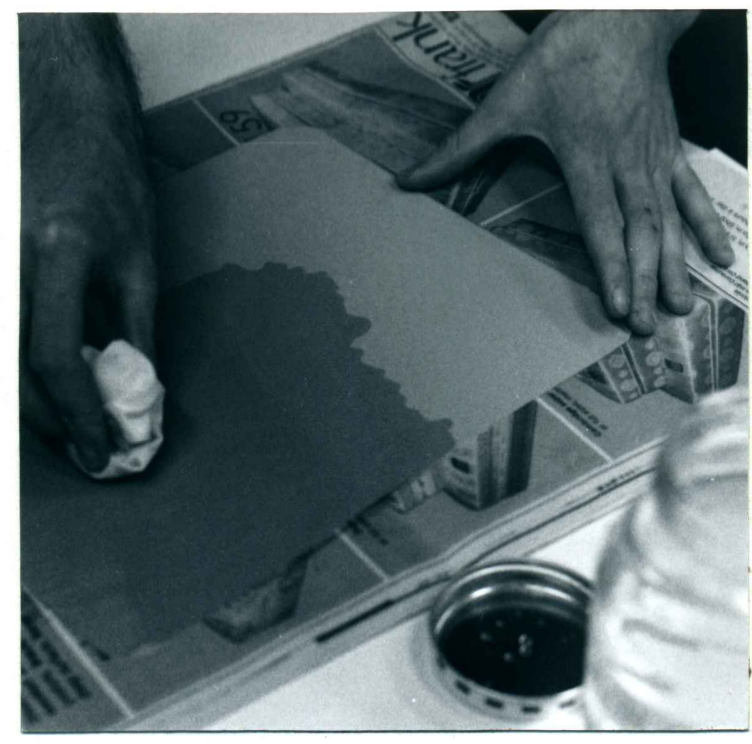

Fig. 6 Counteretching plate

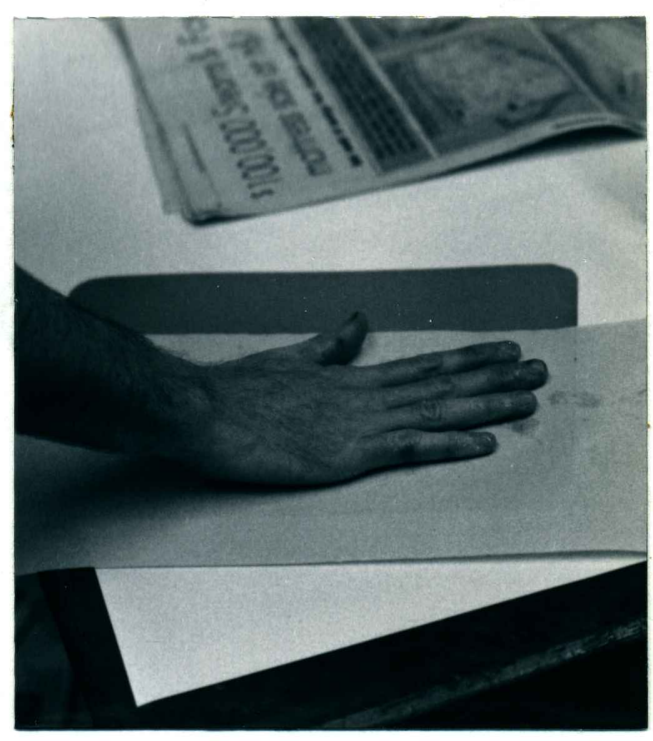

Fig. 7. Blotting plate dry

The plate is now highly sensitive to grease and ready to receive the drawing. At this point any greasy mark made on the surface will print. The plate must be handled carefully now and during the drawing phase to avoid unwanted marks. Plates should be wrapped in clean paper for storage. The drawing should be executed as soon after counteretching as possible. While it is not necessary to rush the drawing, it is advisable to proceed as efficiently as possible with the drawing, etching, and printing before new oxides form. 
Some lithographers prefer to protect the borders of the plate from unwanted smudges and fingerprints with gum arabic. The image border is drawn with red Conte Crayon and a ruler. A thin coat of gum arabic is applied to the plate margins with a brush. When the gum is dry, the actual drawing may begin.

While some students will prefer to draw directly on the plate with the lithographic drawing materials, most will feel more comfortable with some type of preliminary sketch. Red Conte Crayon which is completely non-greasy, may be used to lightly sketch the basic composition on the plate. Mistakes are carefully brushed off with a clean cloth. It is important that the Conte Crayon be applied very lightly or it will clog the pores of the plate and appear as white marks on the finished print.

A more precise guide may be made by outlining the image with Conte Crayon on tracing paper. The tracing paper is placed Conte side down, on the face of the plate and the lines traced with a pencil thus off-setting the Conte on the surface of the plate.

Aluminum plates offer the artist the opportunity to produce a wide range of effects. Techniques may be used alone or combined to produce rich visual effects. Figure 8 shows some of the traditional drawing materials used in lithography. 


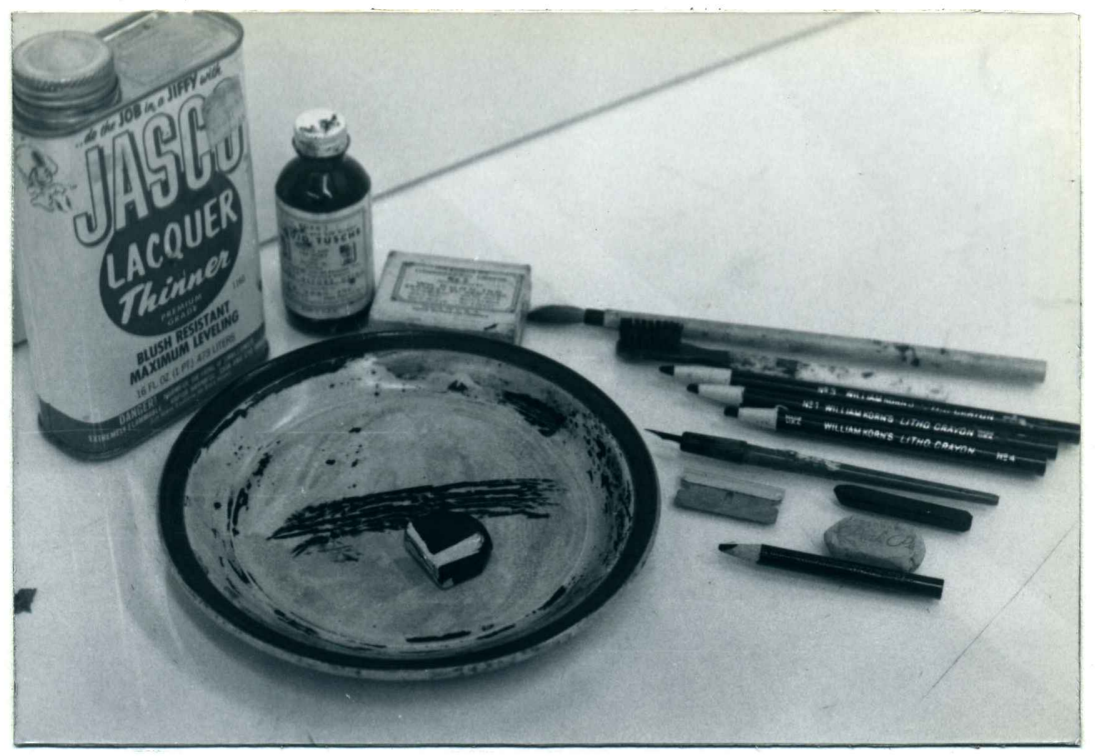

Fig. 8 Lithographic drawing materials

\section{Lithographic Crayon}

Lithographic crayons are manufactured by the William Korn Company and are readily available from lithography suppliers and retail art firms as well. For many, it is the lithographic crayon that produces the characteristic lithographic look. They come in both crayon or pencil form and are available in several degrees of hardness indicated by numbers 0 through 5 . The lower numbers contain the most grease and produce the darkest tones, while the lightest, finest tones are produced with number 5 . Most Tithographers prefer to use the entire range of crayons but others limit themselves to only one or two. A fairly wide range of tones is possible with a number 3 crayon and some teachers may find it more efficient to limit a beginning class to just one grade of crayon.

Many drawing effects are possible with litho crayons from bold, sketchy lines to soft, subtle tones. Tones should be built up slowly 
with multiple strokes and scribbling should be avoided. It is often difficult for the beginner to judge exactly how the middle tones will appear on the finished print since the plate is generally darker than the printing paper will be. Students should try to imagine the tones as they will appear on white paper.

Since the plate is receptive to any greasy mark, students can avoid unwanted smudges and fingerprints by resting their hands on a clean sheet of paper while working on the drawing (Figure 9).

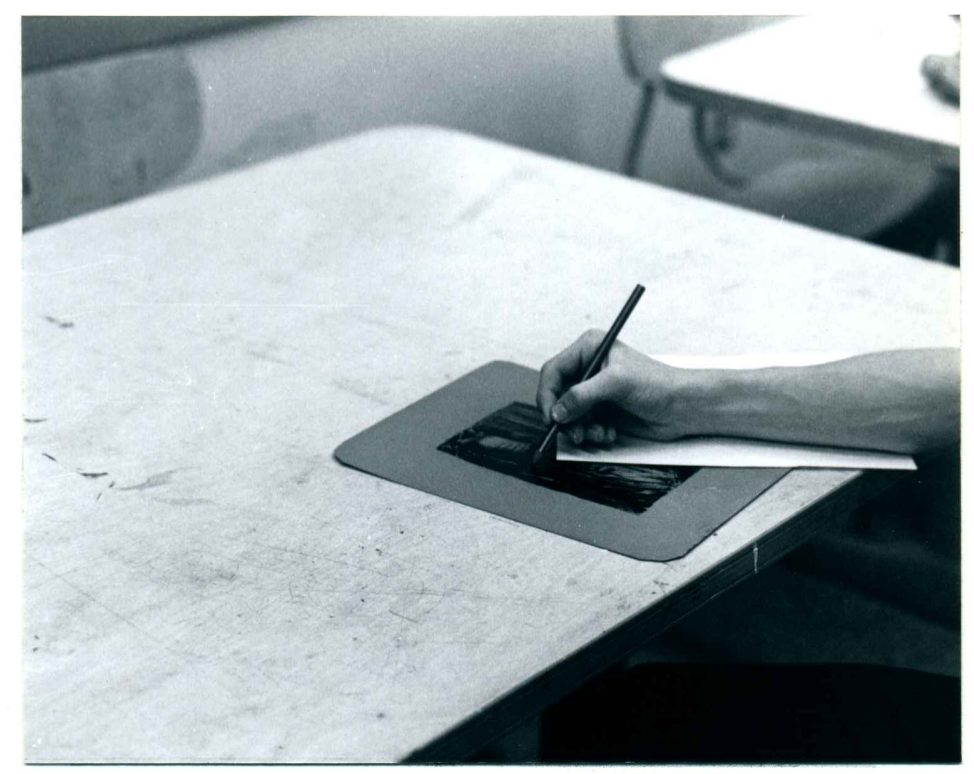

Fig. 9. Protecting the plate while drawing

\section{Koh-i-noor Pencils}

Koh-i-noor "Negro" pencils work very well on aluminum plates, particularly the number 1 pencil. These pencils can be sharpened to an extremely fine point and produce crisp, sharp line drawings. They may also be used to produce tones. Due to the coarse grain of aluminum plates, these pencils as well as all lithographic crayons and pencils must be sharpened frequently. A supply of single-edged razor blades should be kept on hand for sharpening these tools. 


\section{Tusche}

Tusche is a greasy, lithographic drawing material used to produce painterly effects. Tusche manufactured by the Willaim Korn Company is available in liquid or solid form. Liquid tusche may be used as it comes from the bottle for a full strength black or diluted with water for lighter tones. Solid tusche is prepared for painting by first rubbing it against a ceramic or glass plate and then mixing it with a small amount of water until a full strength black is produced (Figures 10 and 11). Charbonnel manufactures an excellent tusche that comes in paste form and must be diluted with water before using. A wide variety of visual effects are possible with tusche and many students find experimenting with tusche to be the most exciting aspect of 1ithography.

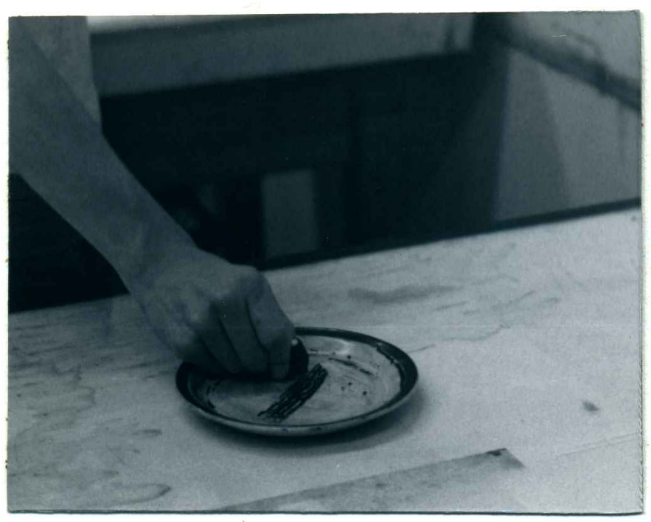

Fig. 10. Rubbing solid tusche on a ceramic dish

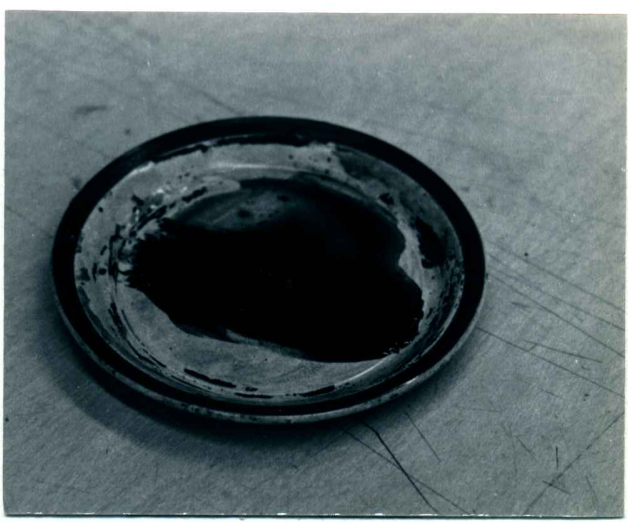

Fig. 11. Solid tusche mixed with water

Both forms of tusche may be applied with a brush or pen to pro duce solid blacks. Tusche may be dry brushed or mixed with varying amounts of water to produce washes, although the accurate control of tusche washes requires some experience. The most dependable wash will be produced by placing a stroke and letting it evaporate naturally. 
Mixing tusche with solvents other than water will produce rich and interesting effects. Water is brushed on to selected areas of the plate and while still wet, tusche that has been mixed with alcohol, turpentine, peroxide, or more water is dropped into the wet area. The puddle is allowed to dry naturally forming many strange and exciting patterns. These effects are more successful with solid tusche and since tusche in either form is fairly expensive, teachers may wish to limit a beginning class to the more versatile solid tusche.

Salt may be sprinkled on a wet tusche area and will cause the tusche to draw around each grain producing white dots ringed with black. Spatter effects are created by dragging a tusche loaded toothbrush over a wire screen or flicking the brush with a knife. Selected areas may be masked out with pieces of paper.

It is not always easy to predict how a particular tusche technique will look in the final print. It may be helpful for the class as a whole to produce an experimental test plate using a wide variety of techniques, then process and print it before each student embarks on his individual project.

All the techniques described may be used alone or combined. Litho crayon, Negro pencil, and tusche offer the beginning student an enormous range of possibilities, however many other lithographic techniques may be used successfully on aluminum plates. Other methods including photo-lithography and color lithography that are beyond the scope of this thesis are described in several books on lithography listed in the biblography. 
PREPARING THE ALUMINUM PLATE FOR PRINTING

When the drawing is completed, the plate must be chemically prepared for printing. The process is traditionally known as etching but it is not the same procedure as etching a copper or zinc plate for an intaglio print. Jules Heller refers to this step as desensitizing rather than etching; however, most 1 ithographers continue to refer to the procedure as etching. 8

The chemicals in the etch prepare the drawn areas of the plate to attract the greasy printing ink and the non-image areas to attract water and repel the ink.

Etching the plate is a critical part of the total process and should be done as carefully as possible. The teacher should assist the beginning student throughout all phases of etching and printing the plate since an error can easily destroy the drawing. The following materials should be assembled for the etching procedure: talc, gum arabic, etch solution, dry cheesecloth, brushes, turpentine, asphaltum, water, bowls, sponges, ink and the roller (Figure 12). If printing will immediately follow the etching, the proofing and printing paper must be on hand as well.

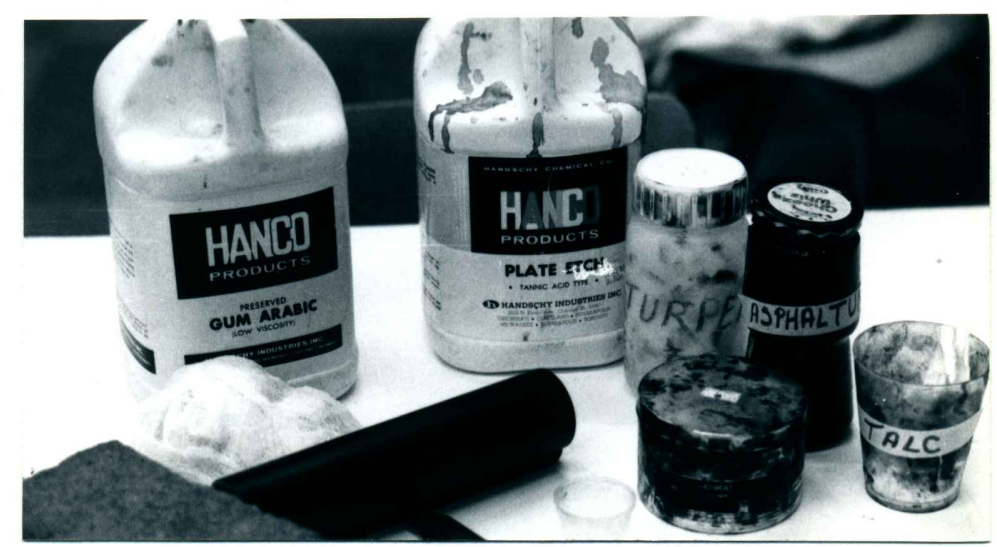

Fig. 12. The etching materials 
Etching the plate may be done on the press bed of a litho press or if using an etching press, the plate may be prepared on any smooth, easy to clean surface. Etching and inking a plate is usually not done on the bed of an etching press because it is generally too high to work comfortably and any ink and water left on the bed will ruin the blankets.

The plate is first secured to the support by sprinkling a small amount of water under the plate and allowing suction to hold the plate in place.

The image is dusted with talc and the excess removed with a clean cloth. Lithographic talc is available from printmaking suppliers. Figure 13 shows the plate being dusted with talc.

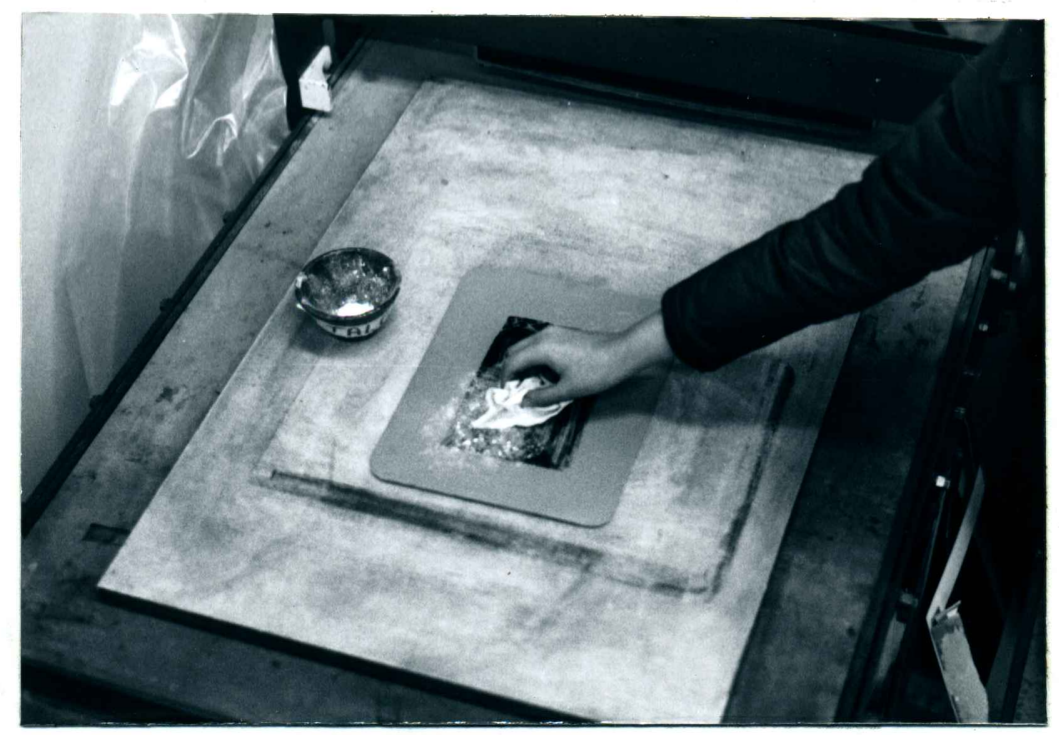

Fig. 13. Dusting the plate with talc

While some lithographers prefer to mix their own etches, many commercially prepared etches are available. A simple plate etch may be made with Hanco Tannic Acid Plate Etch MS214 and gum arabic. While this solution does contain a small amount of tannic acid, it is safe 
for use in a school setting. Tannic acid is toxic only if ingested and this etch does not irritate the skin or have harmful fumes. ${ }^{9}$

A11 prints included in this thesis were produced with MS214. Formulas for other etches will be found in Appendix B.

The character and grease content of the drawing will determine the strength of the etch as well as the length of time that the etch remains in contact with the drawing. Generally speaking, the darkest areas of the drawing have the heaviest grease content and will require the strongest etch. MS214 may be used fu11 strength for the dark areas or diluted with gum arabic for the lighter passages. With experience, the teacher will be able to select the proper etch for each drawing. The chart below is a general guide for etch mixtures for various types of drawings using. MS214 and gum arabic. Figures 15 and 16 illustrate various drawing techniques and the strength of the etch used for each.

\begin{tabular}{|c|c|c|c|}
\hline $100 \%$ MS214 & $\begin{array}{l}75 \% \text { MS } 214 \\
25 \% \text { gum arabic }\end{array}$ & $\begin{array}{l}50 \% \text { MS214 } \\
50 \% \text { gum arabic }\end{array}$ & $\begin{array}{l}25 \% \text { MS214 } \\
75 \% \text { gum arabic }\end{array}$ \\
\hline $\begin{array}{l}\text { Fult strength } \\
\text { tusche }\end{array}$ & $\begin{array}{l}\text { Medium tusche } \\
\text { wash }\end{array}$ & $\# 3,4$ crayon-med. & $\begin{array}{l}\# 4,5 \text { crayon- } \\
\text { light }\end{array}$ \\
\hline$\# 0,1,2$ crayon & $\begin{array}{l}\text { \#3 crayon-dark } \\
\text { Negro pencil- } \\
\text { dark }\end{array}$ & $\begin{array}{l}\text { Negro pencil- } \\
\text { med. } \\
\text { light tusche } \\
\text { wash }\end{array}$ & $\begin{array}{l}\text { Negro pencil- } \\
\text { light }\end{array}$ \\
\hline
\end{tabular}

Fig. 14. Etching chart for aluminum plates

A drawing executed with a single technique and with little tonal variation may be etched with a single mixture of etch. The mixture is poured on the plate and gently moved over the surface of the plate 



Fig. 15 Some drawing techniques possible on aluminum plates printed on Arches Buff paper 


\begin{tabular}{|c|c|c|}
\hline $\begin{array}{l}\text { \# } 1 \text { Litho } \\
\text { pencil } \\
100 \% \text { MS } 214\end{array}$ & $\begin{array}{l}\text { Ful1 Strength } \\
\text { tusche applied } \\
\text { with brush and pen } \\
100 \% \text { MS } 214\end{array}$ & $\begin{array}{l}\text { Full strength tusche } \\
\text { sprinkled with salt } \\
100 \% \text { MS } 214\end{array}$ \\
\hline $\begin{array}{l}\text { \# } 3 \text { Litho pencil } \\
\text { 75\% MS214 } \\
\text { 25\% Güm arabic }\end{array}$ & $\begin{array}{l}\text { Tusche diluted } \\
\text { with water dropped } \\
\text { into puddle of water } \\
\begin{aligned} 100 \% \text { MS214 - darks } \\
75 \% \text { MS214 - lighter } \\
\text { areas }\end{aligned}\end{array}$ & $\begin{array}{l}\text { Tusche mixed with } \\
\text { alcohol dropped into } \\
\text { puddle of water } \\
100 \% \text { MS } 214\end{array}$ \\
\hline $\begin{array}{l}\text { \#3 Litho pencil for } \\
\text { the darks } \\
\text { \#4 Litho pencil for } \\
\text { the light area }\end{array}$ & $\begin{array}{l}\text { Tusche spatter } \\
\text { Area masked with paper }\end{array}$ & \#1 Negro penci 1 \\
\hline $\begin{array}{l}50 \% \text { MS214 - darks } \\
25 \% \text { MS214 - 1ight }\end{array}$ & $\begin{array}{l}\text { 75\% MS } 214 \\
25 \% \text { Gum arabic }\end{array}$ & $\begin{array}{l}50 \% \text { MS214 } \\
50 \% \text { Gum arabic }\end{array}$ \\
\hline $\begin{array}{l}\text { Tusche mixed with } \\
\text { peroxide dropped } \\
\text { into puddle of water } \\
50 \% \text { MS214 } \\
50 \% \text { Gum arabic }\end{array}$ & $\begin{array}{l}\text { \# } 3 \text { 1 itho crayon } \\
\text { for background and } \\
\text { fu11 strength tusche } \\
50 \% \text { MS214 - background } \\
50 \% \text { Gum arabic } \\
75 \% \text { MS214 } \\
25 \% \text { Gum arabic - tusche }\end{array}$ & $\begin{array}{l}\text { \# } 5 \text { Litho pencil } \\
\text { 25\% MS214 } \\
75 \% \text { Gum arabic }\end{array}$ \\
\hline
\end{tabular}

Fig. 16. Drawing materials and etch strengths

with the fingers or a brush (Figure 17). Drawings with a wide range of techniques and tones must be spot etched. The appropriate etch for each passage is mixed and the printer begins by brushing the strongest etch on the darkest areas then moves to the lightest areas with the weakest etch. Figure 18 illustrates spot etching. 


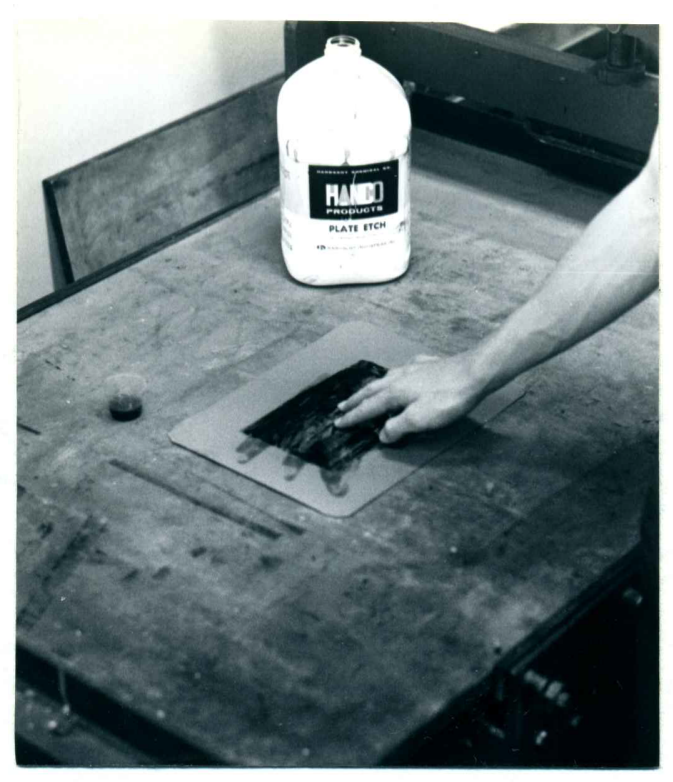

Fig. 17. Etching the plate

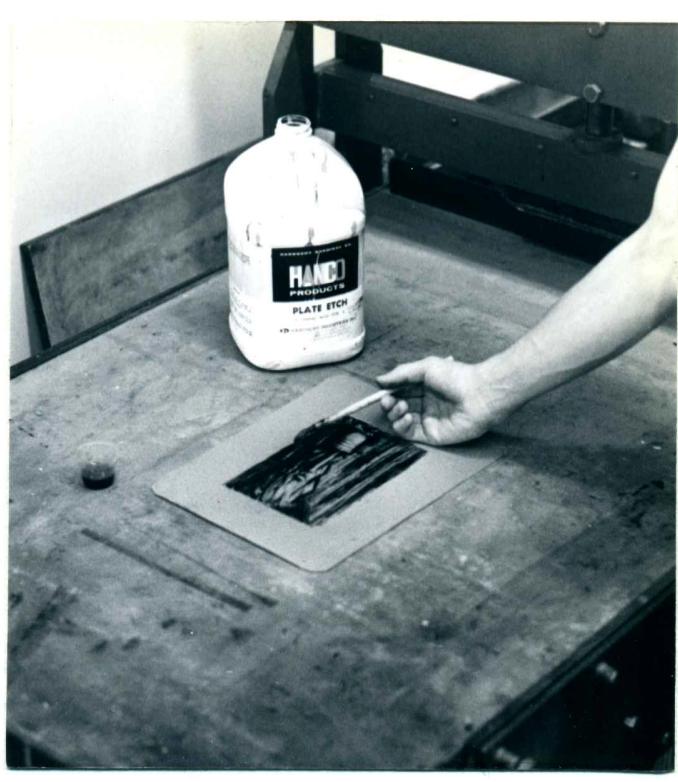

Fig. 18. Spot etching the plate

There must be enough etch to flow over the entire plate, not just the image area. The etch must desensitize both the image and the nonimage areas. An ounce of etch solution should be sufficient for plates up to $16^{\prime \prime} \times 20 "$.

The etch should remain in contact with the drawing from two to five minutes. The spot etching method allows the strongest etch to remain in contact with the darkest areas for the greatest length of time.

The etch is removed from the plate with cheesecloth. Two or three pieces of cheesecloth are formed into pads and one is used to quickly remove the excess etch. A clean pad is moved in a quick, circular motion over the entire plate to buff the etch down to a smooth, even film (Figure 19). 


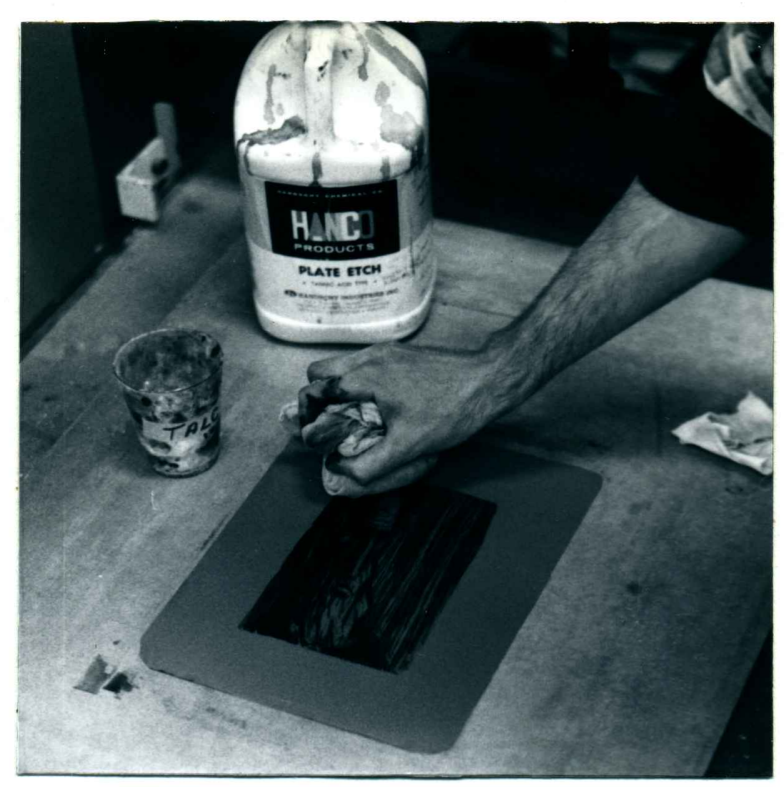

Fig. 19. Drying the etch

It is important to work quickly at this point to insure that the etch dries evenly to the thinnest film possible. The surface of the plate will feel extremely smooth with no trace of stickiness. The cheesecloth pads should be washed in cool water at this time and hung to dry as they may be used many times.

There are several points during the etching process when work may stop and the plate stored until later. There are other procedures that cannot be interrupted. After the etch has been dried to a thin film, the plate may be wrapped in clean paper and stored until it is more convenient to continue. It is important to plan work with this in mind, particularly in classes with limited time.

\section{WASH OUT}

Lithographic drawing materials contain pigment that must be removed before the litho ink is applied. The excess pigment is removed 
from the drawing with turpentine or lithotine. A soft, clean rag saturated with the solvent is passed over the plate until the image appears nearly white (Figures 20 and 21).

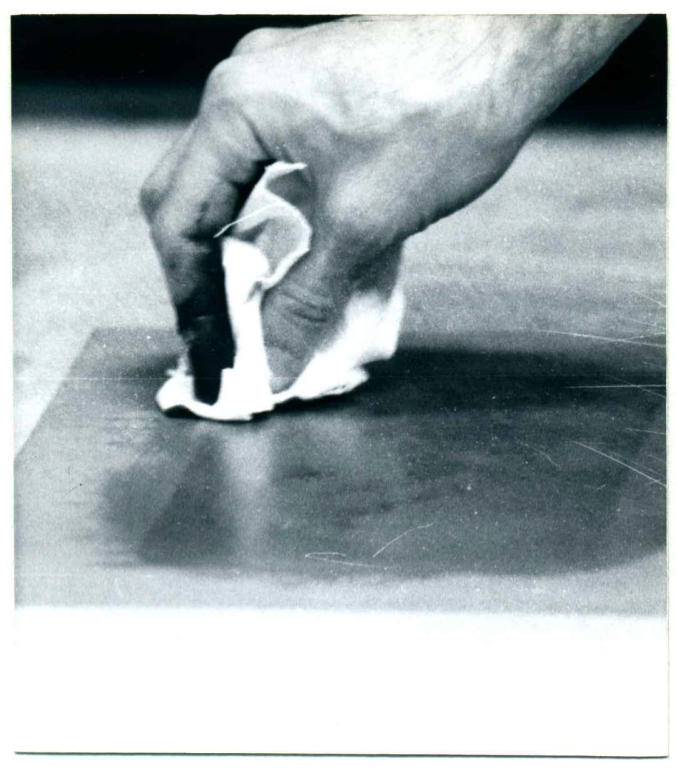

Fig. 20. Washing out the image

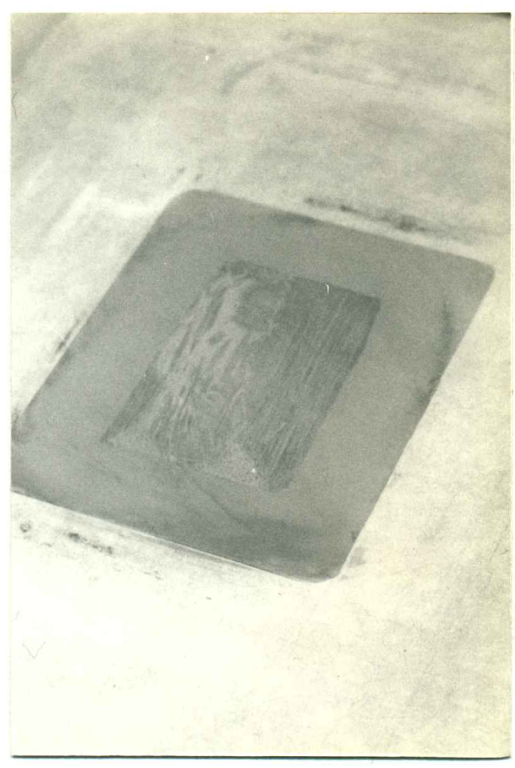

Fig. 21. The image washed out

Only the drawing material is affected by the solvent as the thin coat of etch has formed a protective mask over the non-image areas. Litho crayon and heavy tusche areas wash out completely, but Negro pencil does not and care must be taken not to rub too vigorously or the image will be damaged.

\section{PRINTING BASE}

A printing base is applied at this time to increase the receptivity of the image area for the greasy printing ink. Asphaltum, thinned to the consistency of heavy cream, is an excellent printing base. Asphaltum is used in other printmaking procedures and is available in pints or quarts from printmaking suppliers. A small amount of asphaltum (Figure 22) is poured on the plate and rubbed into the image 
with a clean cloth. The asphaltum is allowed to dry. For those who may desire an extremely large edition of prints, a lacquer base may be applied in addition to the asphaltum. See Appendix $D$ for the lacquer method.

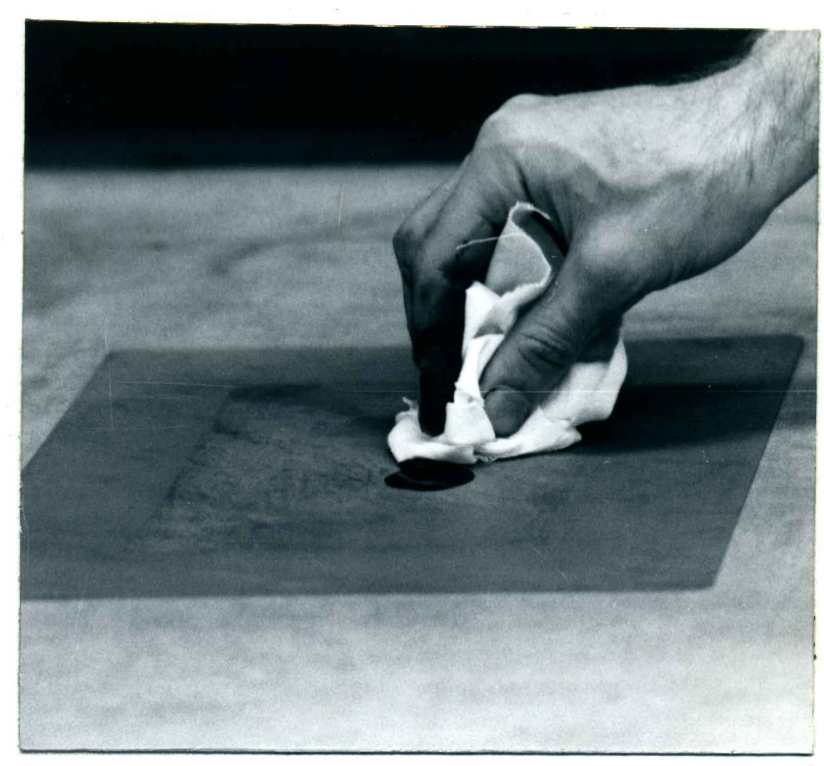

Fig. 22. Applying asphaltum to the plate

When the printing base has dried, the plate may be stored for future use. The asphaltum has formed a protective coating over the image area and the gum mask protects the non-printing area.

\section{ROLL UP}

The ink and roller must be prepared and ready for the roll up process. Lithographic ink is manufactured by several firms, but the most readily available ink is manufactured by Graphic Chemical Company. The ink may be purchased directly from the manufacturer or from any lithography supplier. Graphic Chemical makes several types of ink but a good a11-purpose ink is Senefelder's Crayon Black \#1803. This ink may be used successfully for both the roll up and for the final printing. 
A small amount of ink is removed from the can with an ink knife. The ink must be worked with the knife to reduce its stiff consistency. When the ink is ready, it is spread in an extremely thin film on the ink slab. The roller in passed over the ink until a thin, even layer of ink is deposited on both the slab and the roller. With experience, the printer will be able to accurately judge the proper amount of ink but it is always better to begin with too little rather than too much. Excess ink can quickly ruin a print.

After the ink has been prepared, it is time to wash off the gum mask and roll up the image with ink. It is important to have everything ready and to proceed rapidly at this point. Two bowls of water and two sponges are necessary. A sponge saturated with water is quickly passed over the entire plate. The sponge is rinsed in the bowl reserved for soiled water and the procedure repeated until all traces of gum arabic are removed (Figure 23.). Only the brown, asphaltum image will remain.

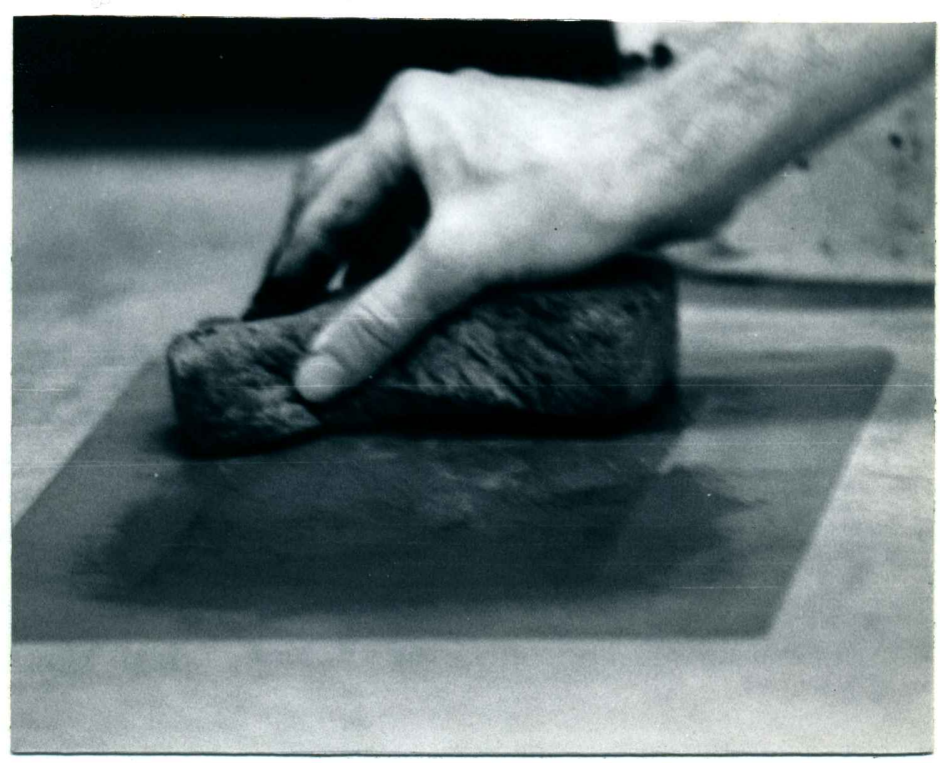

Fig. 23 Removing the gum with water 
The second sponge is dipped into the clean water and wrung nearly dry. This sponge is used to maintain a thin, even film of water over the entire surface of the plate during the inking. It will take some experience to judge the optimum amount of water needed. Too little water will cause the ink to adhere to non-image areas and too much water will cause the plate to repel the ink. The roller, charged with ink, is passed over the drawing area several times. The printer continues to charge the roller with ink, wet the plate, and pass the roller over the image until the drawing looks like the original (Figures 24, 25, and 26).

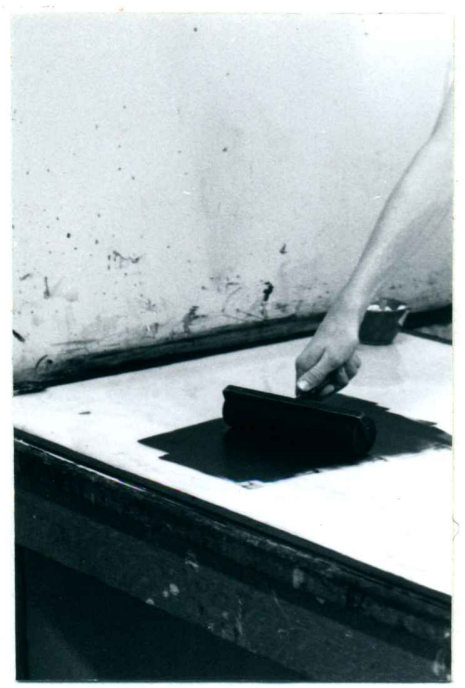

Fig. 24 . Charging

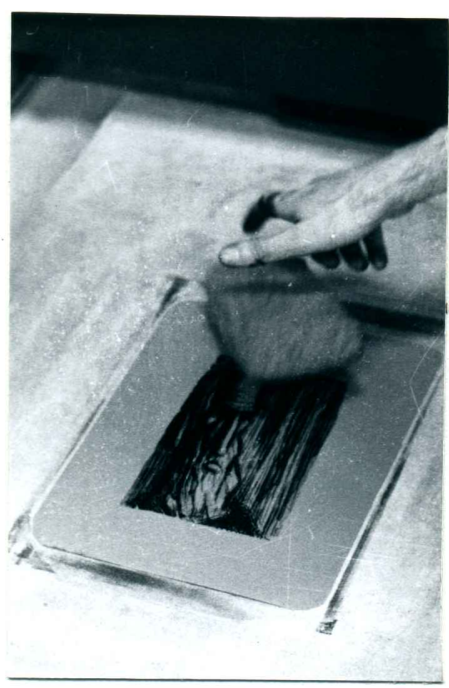

$\frac{\text { Fig. } 25}{\text { the plate }}$ Wetting

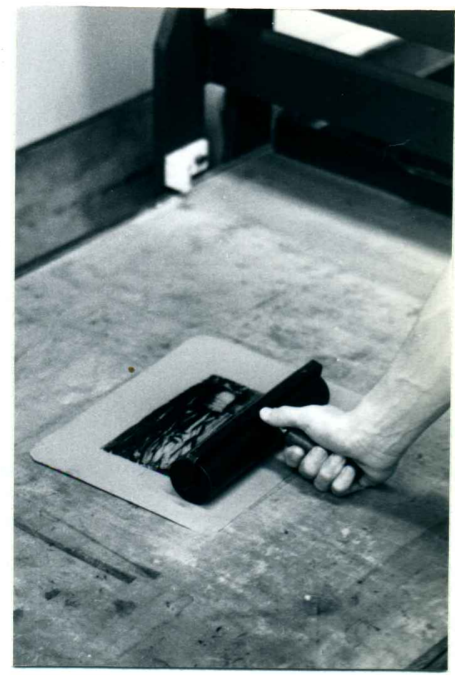

$\frac{\text { Fig. } 26}{\text { the plate }}$ Inking

It is very helpful, even for experienced lithographers to have assistance for the roll up and for the final printing. One person generally handles the inking while the other person keeps the plate properly damp.

At this point some minor correction can be made. Although major deletions and additions are possible on aluminum plates, the process 
involves several additional steps and is not always reliable. Major changes should be attempted only by skilled lithographers but it is relatively easy for beginners to remove minor smudges or fingerprints. A careful application of lacquer thinner will remove large unwanted areas but care must be taken not to allow the thinner to creep into other areas. Weldon Roberts Retouch Sticks, available from lithography suppliers are designed specifically for removing spots on aluminum plates or a Pink Pearl eraser may also be used for this purpose.

\section{THE SECOND ETCH}

After the image has been inked and minor corrections made, the plate is ready for the second etch. At this point, the drawing is only partially stabilized and a second etch is necessary to reinforce the chemical reactions that have taken place on the plate. The printer also has the opportunity to assess the correctness of the first etch.

If the inked image looks like the original drawing after the roll up, then the strength of the etch and the length of time that it was left on the plate should remain the same. If the image looks somewhat lighter than the original, then the strength of the etch should be decreased; i.e., more gum arabic is added. If the inked image appears darker and particularly if certain areas seem to be filling in, the etch should be stronger, i.e., more MS214 is added.

After the etch has been mixed, the plate is talced as before and the etch applied to the surface of the plate. The etch is buffed to a thin, even film with cheesecloth pads. The drawing is washed out with turpentine and rubbed up with asphaltum. At this point the plate 
may be stored for printing at a later time if desired, or printing may proceed immediately.

\section{PRINTING}

Prior to printing, the proofing and printing paper should be cut or torn to size. Paper should be larger than the drawing but smaller than the plate. The large margins of the plate keep the paper clean and dry as well as allowing space for placement of register marks for centering the paper.

The gum mask is removed with water and the image is rolled up with ink. The plate is now ready for printing. Aluminum plates may be printed on either the traditional litho press or on an etching press.

Printing on a litho press

The plate should already be secured with a little water to the bed of the press, or if necessary, to a plate support. After the image has been rolled up, a piece of newsprint is placed over the image area. The first few prints are usually light so inexpensive newsprint is used until the printed image looks like the original. A clean blotter is placed on top of the paper and a greased:tympan is placed over the blotter. The tympan is a sheet of plastic or pressboard that comes in direct contact with the scraper. It must be greased to allow the scraper bar to glide effortlessly across it. Tympan grease is available from litho suppliers but industrial cup grease may be used and even petroleum jelly is satisfactory.

The scraper is a wooden bar covered with leather that slides along the tympan pressing the paper against the inked plate. Scrapers must 
be at least as large as the printing paper but smaller than the plate. If a teacher wants to eliminate the need for many different scrapers, plates could be cut to a uniform size for all members of the class.

The press bed is moved until the edge of the plate is directly under the scraper bar. The press lever is lowered so the scraper is in contact with the plate and the pressure screw is tightened. Once the proper pressure has been determined, the pressure screw need not be adjusted again. The plate is rolled through the press in one continuous motion until the scraper reaches the other edge of the plate. The lever is released and the press is returned to the starting position. The tympan and blotter are removed, and the first proof is carefully pulled from the plate. Figures 27,28 , and 29 illustrate three stages in the printing process.

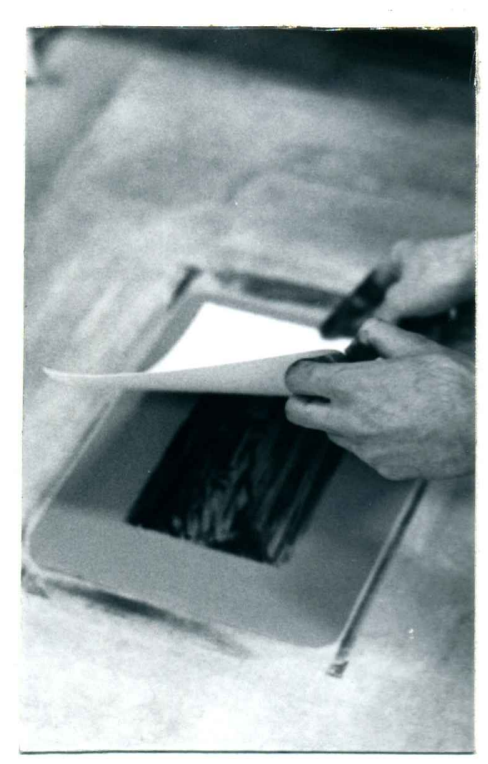

Fig. 27. Centering

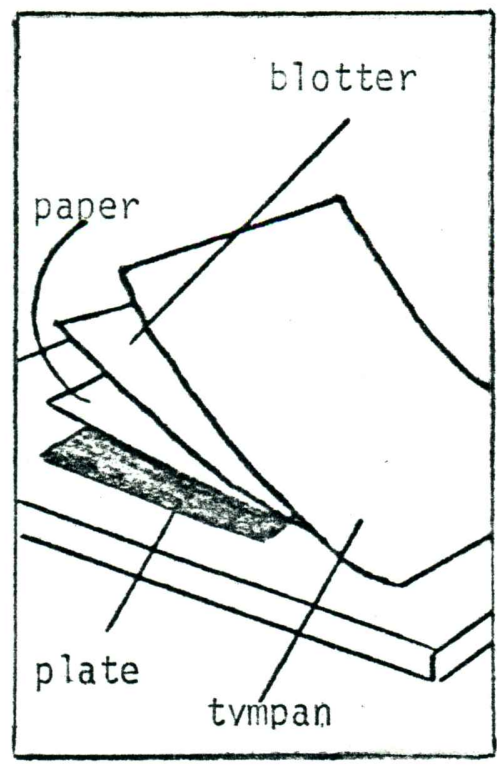

Fig. 28. Plate ready for printing on press

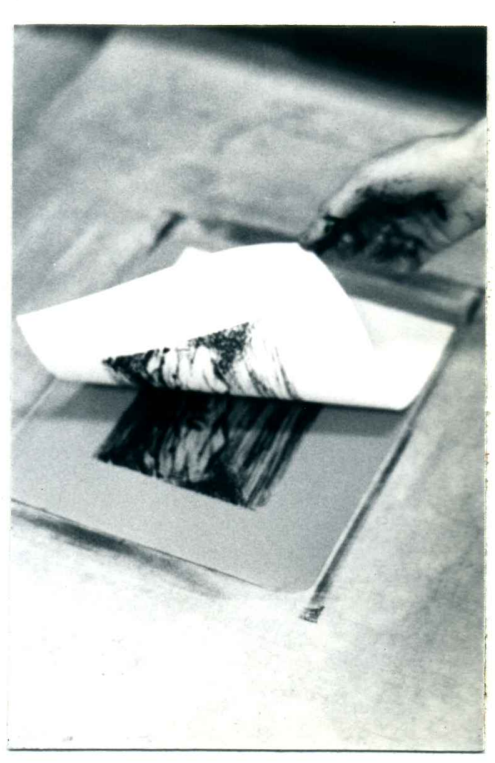

$\frac{\text { Fig. } 29 .}{\text { the print }}$ Pulling

The plate should be dampened with clean water and the first proof examined. It will probably be too light. It is normal for the first 
few proofs to be much lighter than the original and beginners must resist the temptation to add excessive amounts of ink or apply too much pressure.

The entire wetting and inking process is continued and a second proof is pulled. If this proof is no darker than the first, the amount of ink and pressure may be gradually increased until the richness of the original drawing is achieved on the paper. For each print, the printer will continue to charge the roller with ink, wet the plate, ink the image, and print until the desired number of prints has been reached. With experience the optimum amount of water, ink, and pressure wi11 be determined.

\section{Printing on the etching press}

If an etching press is used to print the edition, the wetting and inking of the plate should be done on a smooth surface, such as a piece of glass, situated next to the inking slab. When the plate has been properily inked, it is moved to the etching press and centered on the bed of the press. The printing paper is centered on the plate and blotters or a piece of illustration board is placed on the top of the paper. The blotters should be at least as large as the plate. The blankets are lowered over the plate and the pressure is set by adjusting the pressure screws situated on top of the press. Figure 30 shows the plate covered with printing paper and blotters before the blankets have been lowered.

The bed of the press is rolled through the press in one continuous motion (Figure 31). The blankets and blotters are removed and the print is carefully peeled from the plate. The plate is moved back to 
the inking area and wetting and inking continue as usual. It is advisable to dry the bed of the press with a clean cloth after removing the plate.



Fig. 30. Plate ready

for printing

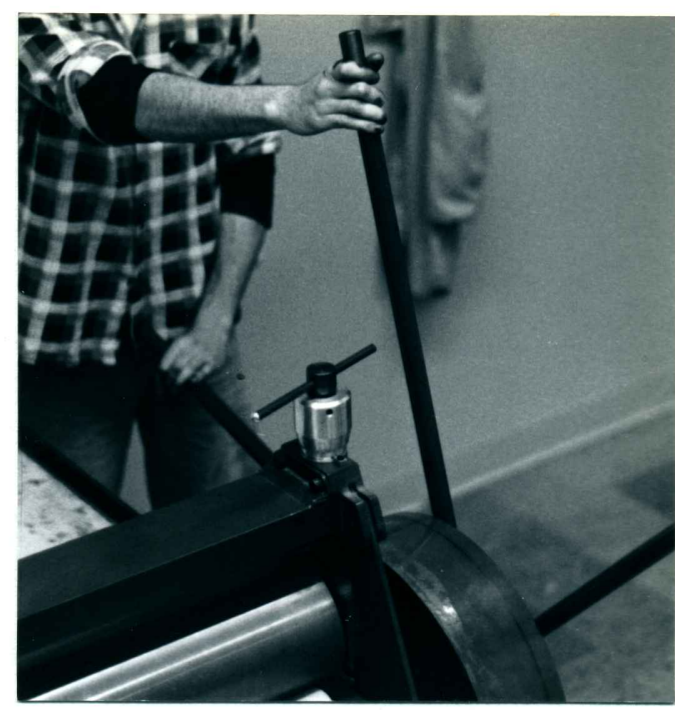

Fig. 31. Operating the etching press

\section{DRYING AND STORING}

The ink on the finished prints must be allowed to dry. Portable drying racks are ideal but a line with clips may be strung and the prints hung until dry.

Aluminum plates may be stored and additional prints completed at a later time. The plate must first be inked as if for printing and then dusted with talc. Pure gum arabic is applied to the entire surface and wiped down to a thin coat with cheesecloth. After storage, it is advisable to apply an additional protective coat of gum arabic over the old gum mask. To open the plate for printing, the old ink is washed out with solvent, the image is rubbed up with asphaltum, and the gum mask removed with water. Inking and printing then proceed as usua 7. 
PROBLEMS

One of the most common problems in aluminum plate lithography is the tendency for parts of the image to fill in. Many beginners find the rich blacks produced in lithography so appealing that they often attempt to increase the blackness by overinking. The ideal print should be no darker than the original drawing and overinking can cause rapid filling in of the image until all subtlety is lost. If the drawing appears to be filling in and overinking is suspected, the amount of ink should be reduced and hopefully the prints will return to their original clarity.

Sometimes, particularly in dark areas such as heavy tusche washes, portions of the drawing fill in and overinking is not the cause. It may be helpful to use a fountain solution in place of water to wet the plate. A fountain solution acts as a mild etch fortifying the nonprinting areas each time it is used. It can be made by mixing onehalf to one ounce of MS214 to a quart : of water to produce a moderate to strong solution. Too strong a solution or too frequent use may damage the delicate parts of the drawing so the printer must examine the plate closely and use the fountain solution only when it is necessary. Fountain solutions should be mixed fresh for each use since they tend to spoil rapidly.

There are times when the image looks good on the plate but continues to print too light. The pressure may be increased somewhat but excessive pressure should be avoided. If a slight increase in pressure does not remedy the situation, dampening the printing paper will often help to bring out all areas of the print. Water can be sprayed from 
an atomizer or sponged on to the paper and the excess blotted with paper towels or blotters. A large brush may also be used to dry the paper. No water should be left standing on the surface of the paper. Many 1ithographers, in fact, prefer to print from damp paper all of the time. Damp paper will curl after printing and prints need to be stacked between paper towels or blotters and weighted until dry and flat.

Sometimes beginners will forget to wet the plate before applying the ink and the entire plate becomes black. If this should occur, the plate is immediately dampened with water and the roller quickly snapped across the surface of the plate picking up the excess ink. 
CHAPTER VI

\section{PAPER PLATE LITHOGRAPHY}

Litho-Sketch is the brand name of a well-known paper 1ithographic plate manufactured by the Anthony Ensink Company. The plates are available from general printmaking suppliers and from the manufacturer. They are available in sizes ranging from $6^{\prime \prime} \times 9^{\prime \prime}$ to $25^{\prime \prime} \times 36^{\prime \prime}$, and are approximately the thickness of a piece of illustration board. The white side is the lithographic surface that receives the drawing while the yellow side is non-printing. The larger plates are easily cut to any size with a scissors or paper cutter. Inking and printing problems will be reduced if a margin of one to two inches larger than the drawing is maintained on all sides of the plate. Kits containing al1 necessary materials for paper plate lithography are also available from suppliers.

There is no preparation necessary to sensitize the plates for drawing since they come from the manufacturer already highly sensitive to grease and must be handled carefully at all times.

Students who wish to work from a prepared drawing may trace their work easily with paper plates. If a light table is available, the drawing is placed under the plate on top of the light table and the drawing traced on to the white surface of the plate. In the absence of a light table, the plate and drawing may be held up to a window and then traced. Some students prefer to work directiy on the plate and they may draw lightly with an ordinary pencil, erasing any mistakes gently. 
Care must be taken not to press too hard with the pencil causing a depression in the plate since it will show as a white line on the finished print. Erasing must also be done carefully to avoid damaging the surface.

The range of drawing materials and techniques possible on paper plates is considerably less than for aluminum plates, but litho crayon, litho pencil, and tusche may be used.

Lithographic pencils work well on paper plates but work should be limited to number 2,3 , or 4 pencils. Drawing done with the number 1 or number 5 pencils often tends to lift during printing so they should be avoided. Many students feel that a number 3 litho pencil is a good, a11-purpose pencil for paper plate 1ithography. Litho pencils are particularly good for all linear work and editions from ten to fifteen have successfully been printed that closely maintained the look of the original drawing. Delicate tonal work can be done on paper plates, but the number of reliable prints will be 1 imited. Tonal work that is built up slowly with multiple strokes holds up the longest. It is possible to produce white lines on a dark ground by carefully scratching crayon areas with a razor blade.

Liquid or solid tusche may be used successfully on paper plates. Solid tusche is prepared in the same manner as it is for aluminum plates, however with both forms of tusche, only full strength blacks will reproduce. Neither tusche washes nor the effects possible with tusche and various solvents can be accomplished reliably on paper plates. Both dry brush and spatter effects are possible and solid blacks can be painted with a brush or drawn with a pen and tusche. 
Heavy build up of tusche should be avoided as it will create printing problems.

Desensitizing the paper plate is extremely simple compared to the etching procedure for aluminum plates. The desensitizing is done each time that a plate is inked so all inking materials as well as proofing and printing paper must be ready. The pigment from the drawing materials is not washed out nor is there any need for a printing base with paper plates. As soon as the drawing is completed, one may immediately proceed to the desensitizing, inking, and printing of the edition.

The Anthony Ensink Company manufactures an ink specially designed for paper plate lithography that is available from both the manufactuer and other printmaking suppliers. The ink is not as stiff as regular Titho ink and contains driers. Due to the addition of the driers this ink must never be used with a leather roller, but any rubber or plastic roller or brayer is satisfactory. Regular 1ithographic ink may also be used on paper plates but with care. There is a tendency for the image to lift during inking and printing, particularly on delicate tonal areas. Stiff litho ink may hasten this process so it should be rolled on the plate carefully or a small amount of litho varnish may be added to reduce stiffness. The ink should be rolled out in a thin, even film on the inking slab in the same manner as it is for aluminum plates.

Litho-Sketch Plate Solution is all that is needed to prepare the plate for inking. Three parts of the solution are mixed with one part of water. The solution is applied evenly and gently to the entire surface of the plate with a clean, soft cloth (Figure 32 ). 


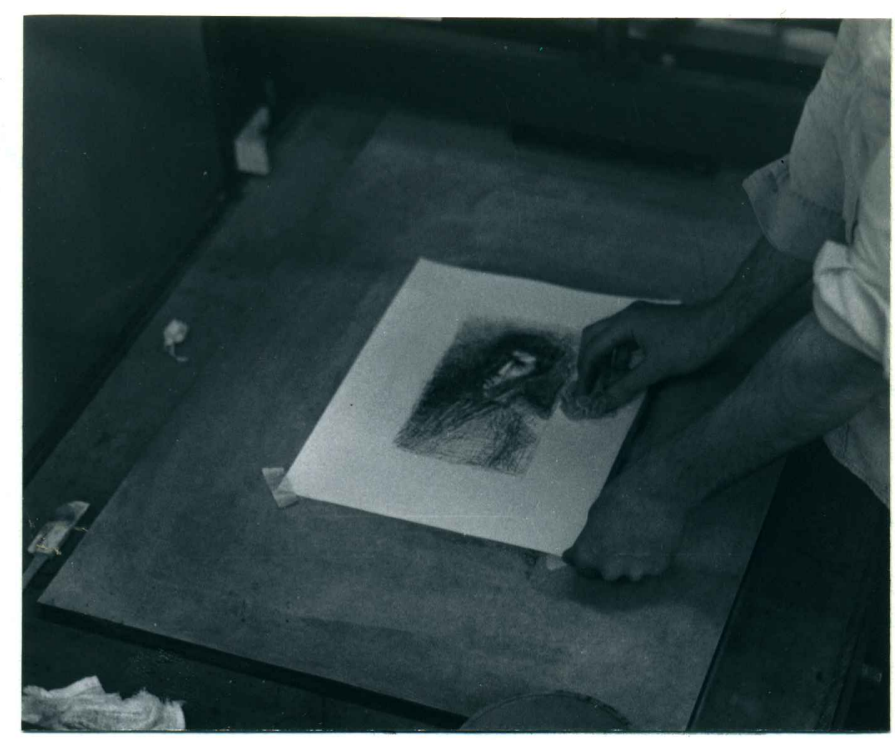

Fig. 32. Applying the prate solution

Occassionally, some of the pigment from the drawing material will streak the plate during this procedure, however it will not affect the final print. Some experience is necessary to judge the proper amount of solution needed. As is the case with all lithography, too much liquid wi11 repel the ink and too little will not protect the undrawn areas.

The roller is charged with ink and passed over the drawing immediately after the plate solution has been applied (Figure 33). This procedure is repeated until the entire image has been inked. The plate may be held in place while inking or the corners taped to prevent slipping. The tape is removed during the printing.

The plate should be fanned dry before the paper is applied (Figure 34). There is a tendency for paper plates to develop wrinkles and even tear if a wet plate is run through the press and these wrinkles will eventually pick up ink and appear as unwanted black lines on the 
finished print. If the plate is fanned dry before printing, the development of these wrinkles and tears will be minimized.

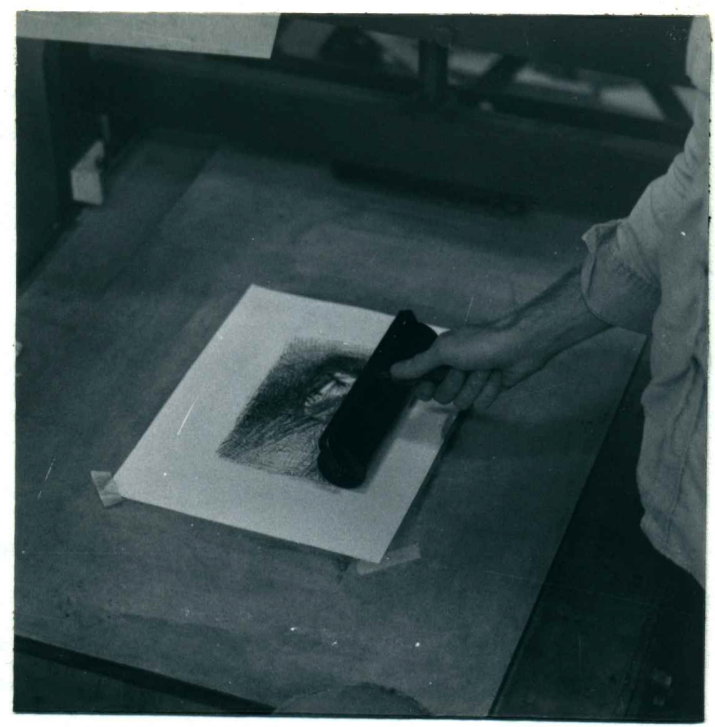

Fig. 33. Inking the paper plate

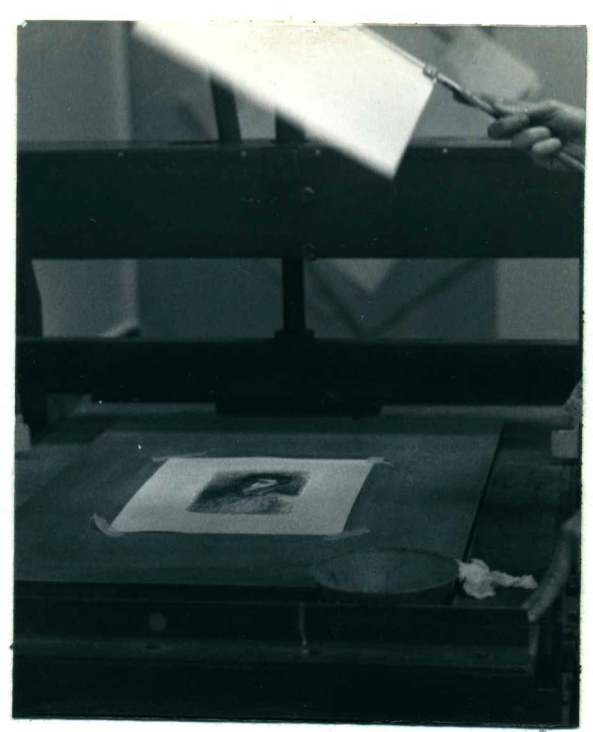

Fig. 34. Fanning the plate dry

When the plate is dry, a piece of newsprint is centered on the plate. Al1 lithographs require a slow initial build up of ink and newsprint or other inexpensive paper is recommended until the print is up to full strength.

Paper plate lithographs are printed on a litho press in the same manner as an aluminum plate. A blotter and greased tympan are placed on top of the printing paper, the lever is lowered, the pressure set, and the plate is cranked through the press. Printing the paper plate on an etching press is also identical to printing an aluminum plate on an etching press.

Paper plate prints tend to reach full strength rapidly and probably only one or perhaps two proofs will be necessary. Proofs and subsequent prints may be examined at length after each printing since there is no need to maintain a damp surface of the plate. 
Applying the plate solution and inking the plate proceed as usual until the desired number of prints has been reached. If printing must be interrupted, it is easy to store the plate and continue at a later time. Before storing the plate, it should be run through the press two or three times without plate solution or new ink. A clean sheet of newsprint is used each time the plate is run through the press to absorb excess ink. The plate should be placed in a plastic bag or wrapped carefully for storage. The Ensink Company makes a gum solution that can be applied to the plate as a protective coating for storage, and is removed with water when further printing is to begin. Experience has shown that merely removing excess ink and storing the plate in a protective wrapper is all that is necessary. When additional pronts are desired, the plate is wiped with the Plate Solution and inked and printed as usuat.

The simplified desensitizing and inking procedure allows the printing of an edition of at least ten prints in under an hour. Although one person can easily manage to apply the plate solution, ink, and print the plate, the process is greatly streamlined when the teacher or another student assists the printer.

\section{PROBLEMS}

The most common problem, associated with paper plate lithography is the tendency for portions of the image to lift during inking and printing. This severely limits the number of accurate prints in the edition. A minimum number of roller passes, minimum press pressure, plus gentle and careful application of the plate solution will prolong 
the life of the drawing somewhat. Drawings built up slowly with multiple strokes using a crayon of medium hardness will last the longest. Careful drawing and printing should produce dependable editions of ten or more prints and some students have successfully printed editions of twenty.

Since the plates come from the manufacturer already sensitized, careful handling during all stages is imperative. Unfortunately, even the most fastidious student sometimes finds unwanted streaks appearing during the first inking that were not apparent before. These may be the result of careless handling during packing or shipping or poor storage conditions. Unwanted marks and smudges may be carefully removed with an ordinary pencil eraser or scraped gently with a razor blade. Care must be taken not to damage the surface of the plate or it will accept ink and print. Some marks may also be removed by vigourously rubbing with the plate solution. This method is most successful if the smudge appears in the margins. 


\section{RECOMMENDATIONS AND CONCLUSIONS}

\section{RECOMMENDATIONS FOR TEACHING PLATE LITHOGRAPHY}

Those familiar with lithography know that frustrations, irritations, and failures are bound to occur even under the best of conditions. Since lithography is a chemical process, a great many factors can affect the final outcome of the print, including the humidity and temperature of the classroom. As students and teachers gain experience with the process many of the problems will be minimized.

With both aluminum and paper plate lithography, many sources of irritation will be reduced by providing sufficient space in the classroom so that etching and printing may be done in a smooth, efficient manner. Teachers may find that setting limits on the size of the prints may be very helpful in this regard, as well as helping to control costs.

Although corrections can be made on both types of plates, it is advisable to prepare students in an introductory class to learn to draw on the plates without the opportunity to make changes. In preparation for lithography, teachers can have students draw with litho crayon on paper to get the feel of the materials. Since litho crayon is difficult to erase neatly even on paper, the students will gain some experience before beginning the actual drawing on the plate.

Most students will enjoy the opportunity to produce multiples of their work but the practical application of printmaking may be an 
additional stimulation. Students can produce lithographs for use as greeting cards, gifts, or for exchanging with their classmates.

The atmosphere created by the teacher when introducing lithography is extremely important in forming the student's attitude toward the process. It is important to stress a craftsmanlike approach to the medium without creating a climate of fear. There is no doubt that sloppy work habits can have disasterous results, but undue emphasis on neatness may destroy some students' enthusiasm immediately.

\section{Choosing Paper Plates or Aluminum Plates for the Classroom}

Perhaps more than any other factor, the element of time will determine which lithographic process is more suitable for a particular classroom situation. Classes limited to one fifty-five minute period each day may find that the time required to process aluminum plates is prohibitive. For this reason alone, paper plate lithography may be preferred. Students who have only fifty-five minutes available to them each day and want to work with aluminum plates will have to etch and print their plates in stages.

Many beginning students have no interest in printing large editions of their work and are perfectly satisfied with five or six prints. For these students, paper plates would be adequate but the student who desires a large, consistent edition of prints must use the aluminum plate method.

Some teachers may wish to provide their students with an introduction to lithography that most closely resembles that practiced in college and art schools. Paper plate lithography will probably appear too simplified for their objectives whereas aluminum plates would be idea 7 . 
The teacher will find it helpful to experiment and gain some experience with both processes but it is particularly important in aluminum plate lithography. The most critical aspect of aluminum plate lithography is the etching process. Teachers should experiment with different types of drawing and varying strengths of etches in order to familiarize themselves with this stage of the process. The etch described in this thesis is a mild solution that was presented because it is simple to prepare and safe to use. There are many other etches available, some of which are described in Appendix B while others can. be found in the books listed in the Bibliography.

Teachers may find it beneficial to have the class as a whole make an experimental aluminum plate, trying various drawing techniques and even including a few fingerprints. Students are fascinated when watching the process for the first time, particulariy as the image is washed out and then reappears when inked.

For very little additional cost, it is possible to equip the classroom for both aluminum plate and paper plate lithographs. Other than the plates themselves, only the desensitizing solutions and two types of ink are needed in addition to the equipment already on hand. A11 students might be required to produce a paper plate litho and those interested in pursuing the process could go on to the more complex aluminum plates. This would be ideal for art classes set up to encourage in-depth exploration in areas of interest. This is the method that was used with those students whose work appears in this thesis. Students might also be allowed to choose one process or the other. Some students may feel one process is particularly suited to their 
type of work, other students may be intrigued and challenged by the technical complexities of aluminum plates, and still others may feel more comfortable with the simplicity of paper plate lithography.

\section{CONCLUSIONS}

The combination of aesthetics and technology characteristic of 1ithography offers the art student an unique experience. The process allows the student to express himself through the familiar medium of drawing plus the opportunity to gain knowledge and respect for craftsmanship.

Aluminum and paper plate lithography provides a relatively low cost, simple introduction to lithography suitable for general art classroom use. The cost and complexities generally associated with traditional lithography can be adjusted so that beginning art students may experience the satisfaction of producing their own lithographs.

The two processes described in this thesis do not pretend to rival stone lithography or the more complex techniques possible on aluminum plates. They do, however, provide young art students with an understanding of the essential characteristics of the lithographic medium and an opportunity to successefully produce an edition of their own prints. 


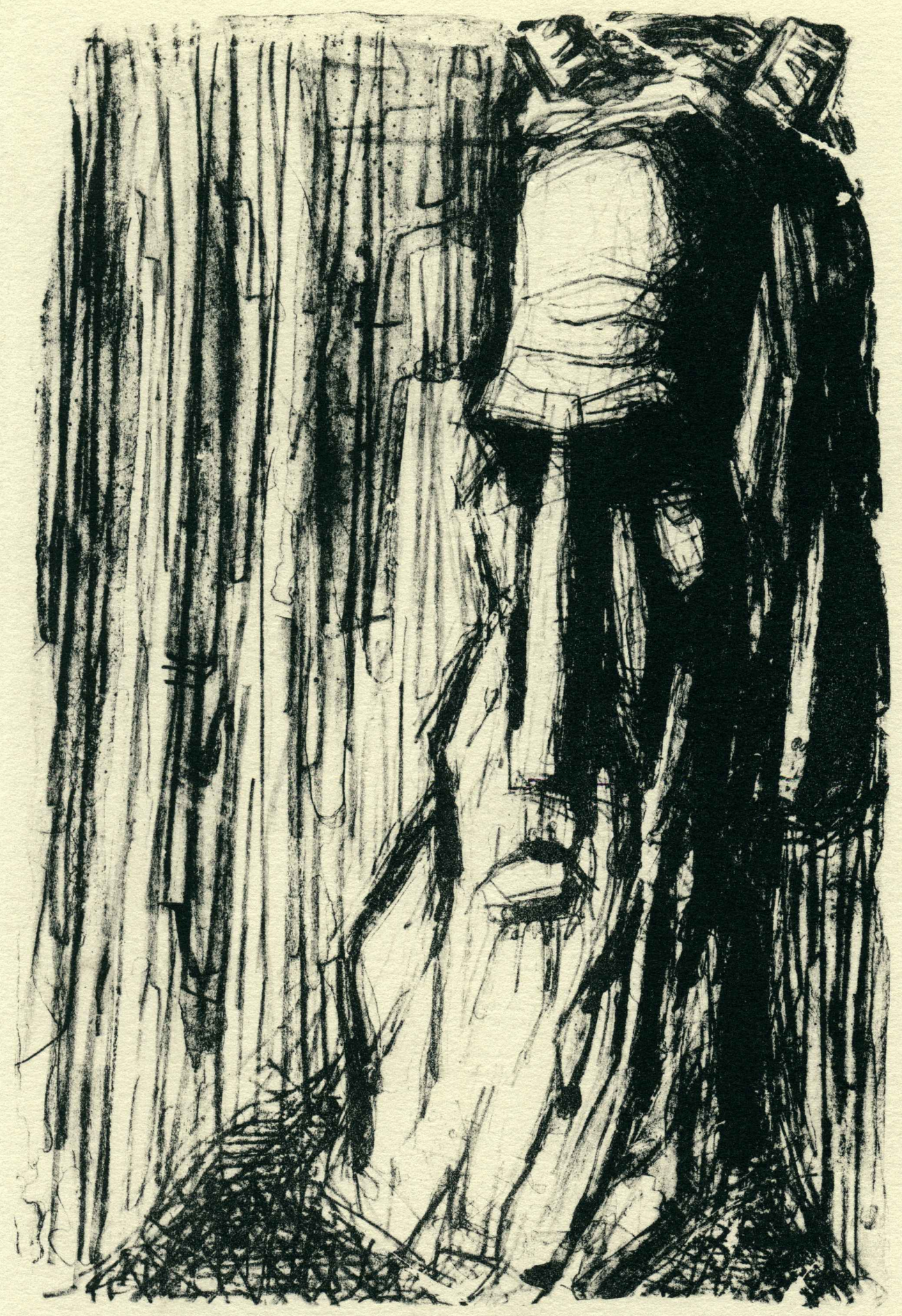

Fig. 35. Aluminum plate lithograph printed on Rives Gray 


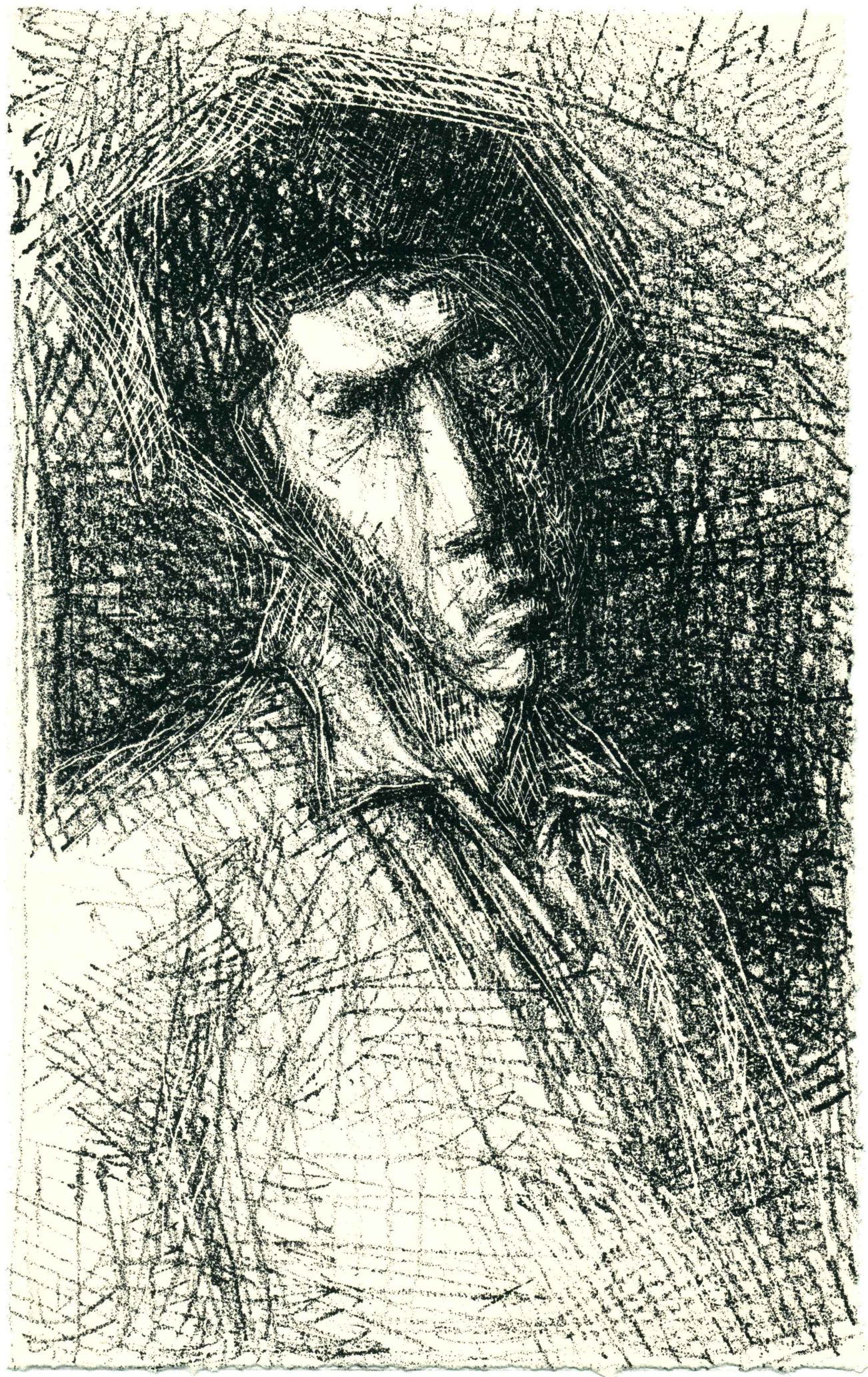

Fig. 36. Paper plate lithograph printed on Domestic Etching 



Fig. 37. Examples of students' aluminum plate lithographs 

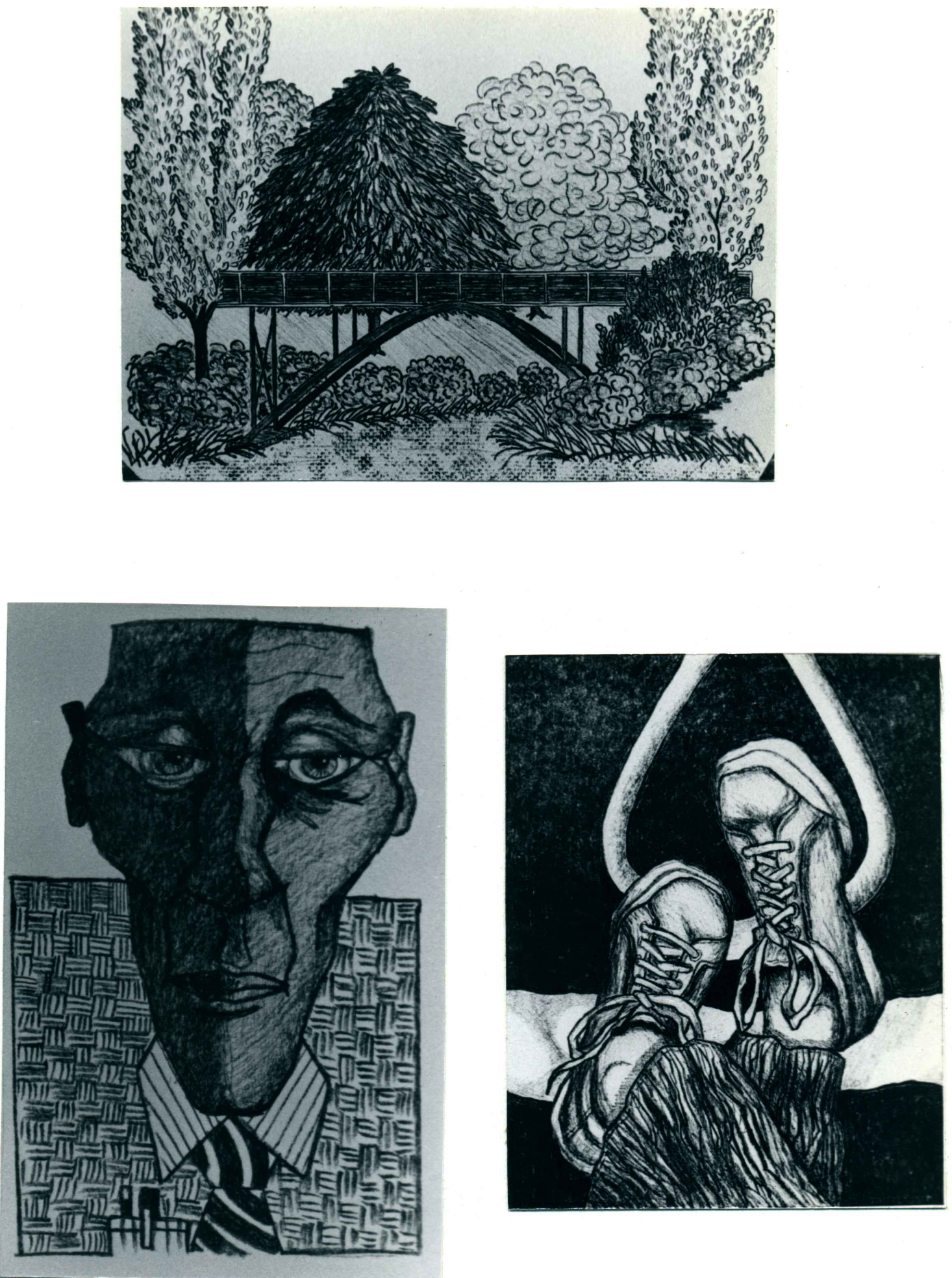

Fig. 38. Examples of students' paper plate 1ithographs 
NOTES

1. William C. Maxwe11, Printmaking: A Beginning Handbook (Englewood Cliffs, N. J.: Prentice-Ha11, Inc., 1977), p. xiv.

2 John Ross and Clare Romano, The Complete Printmaker (New York: The Free Press, 1972), p. 267.

3 Viktor Lowenfeld, Creative and Mental Growth (New York: The Macmillan Company, 1957), p. 338.

${ }^{4}$ Lowenfeld, p. 367.

${ }^{5}$ Michael Knigin and Murray Zimiles, The Technique of Fine Art

Lithography (New York: Van Nostrand Reinhold Co., 1970), p. 5.

${ }^{6}$ Alois Senefelder, A Complete Course of Lithography ( 1819 ; rpt. New York: De Capo Press, 1968), p. 340.

7 Maxwe11, p. 273.

8 Jules Heller, Printmaking Today (New York: Holt, Rinehart and Winston, Inc., 1972), p. 52.

${ }^{9}$ Cherie Moses, et a1., Health and Safety in Printmaking: A

Manual for Printmakers (Edmonton, Alberta: Alberta Labor, Occupational Health and Safety Division, 1978), p. 27.

${ }^{10}$ Information compiled by Myrna Burks.

$11_{\text {Moses, pp. } 56-57 .}$ 
WORKS CONSULTED

Antreasian, Garo, and Clinton Adams. The Tamarind Book of Lithography:

Art and Techniques. New York; Harry N. Abrams, Inc., 1971.

Banister, Manly. Lithographic Prints From Stones and Plates. Totowa,

N. J. : Littlefield, Adams and Co., 1974.

Eichenberg, Fritz. The Art of the Print: Masterpieces, History, Techniques. New York: Harry N. Abrams, Inc., 1976.

Heller, Jules. Printmaking Today. New York: Holt, Rinehart and Winston, Inc., 1972.

Knigin, Michael, and Murray Zimiles. The Technique of Fine Art Lithography. New York: Van Nostrand Reinhold Co., 1970.

Lowenfeld, Viktor. Creative and Mental Growth. New York: The Macmillan Company, 1957.

Maxwe11, William C. Printmaking: A Beginning Handbook. Englewood

Cliffs, N. J.: Prentice-Ha11, Inc., 1957.

Moses, Cherie, et al. Health and Safety in Printmaking: A Manual for

Printmakers. Edmonton, Alberta: Alberta Labor, Occupational

Hea.th and Safety Division, 1978.

Ross, John, and Clare Romano. The Complete Printmaker. New York: The

Free Press, 1972.

Saff, Donald, and Deli Sacilotto. Printmaking: History and Process.

New York: Holt Rinehart and Winston, 19781

Senefelder, Alois. A Complete Course of Lithography. 1819; rpt.

New York: DeCapo Press, 1968. 
Vicary, Richard: Manual of Lithography. New York: Charles Scribner's Sons, 1976. 
APPENDIX A

SELECTED SUPPLIERS FOR. ALUMINUM AND PAPER PLATE LITHOGRAPHY

Dick B 1ick

P. 0. Box 1257

Galesburg, IL 61401 General printmaking supplies including inexpensive presses

Charles Brand Machinery, Inc.

84 East 10th Street

New York, NY 1003

Presses

Craftool Co., Inc.

1 Industrial Road

Wood-Ridge, Ni 07075

General printmaking supplies

Anthony Ensink and Company

400. West Madison Street

Chicago, IL 60606

Paper plate supplies

M. Flax Inc.

10852 Lindbrook Drive

Los Angeles, CA 90024

General printmaking supplies

Graphic Chemical and Ink Co.

728 North Yale Avenue

P. 0 . Box 27

Villa Park, IL 60181

General printmaking supplies

including paper plates

Griffen Company Inc.

1745 East 14th Street

Oakland, CA 94606

Presses

Handschy Chemical Co.

528 North Fulton Avenue

Indianapolis, IN 46202

Lithographic supplies and ink
William Korn, Inc.

260 West Street

New York, NY 10013

Lithographic pencils and tusche

Ra Iph Leber Co., Inc.

P. 0. Box 88700

Tukwi 1a, WA 98188

Ink

New York Central Suppiy Co.

62 - 3rd Avenue

New York, NY 1002

General printmaking supplies

Printmakers Machine Co.

P. 0. Box 71

Villa Pạrk, IL 60181 Presses

Rembrandt Graphic Arts Co.

The Cane Farm

Rosemont, NJ 18556

General printmaking sup-

plies including presses

and paper plates

Daniel Smith Ink Co.

1111 West Nickerson

Seattle, WA 98119

General printmaking sup-

plies 
APPENDIX B

\section{ALUMINUM PLATE ETCHES}

The etch made with Hanco MS214 and gum arabic is relatively mild and simple to prepare. Stronger or more complex etches are often preferred by printmakers working on aluminum plates.

When determining the proper etch for a drawing, it is helpful for the printer to have a means of measuring the strength of the etch solution. An accurate method used to determine the strength of any etch is to measure its acidity. Acidity is measured on the $\mathrm{pH}$ scale from 0-7. The stronger the acid, the lower the pH will be. Short range pH papers, available from chemical companies and some printmaking suppliers are used to measure the acidity of a given etch solution. The pH paper is immersed in the etch mixture for a few seconds. When it is removed, the color of the paper is compared with the pH color chart provided with the product. The use of $\mathrm{pH}$ papers allows the printer to determine the strength of an etch solution and is helpful in preparing the proper etch for each portion of the drawing.

Full strength MS214 has a pH value of 2.5-3.0. Although the acidity of this etch can be reduced by the addition of gum arabic, MS214 cannot be made any stronger than pH 2.5. Lithographers who may prefer a stronger etch must use some other etch formula.

A simple etch commonly used for aluminum plate lithography is made by mixing one ounce of phosphoric acid to one gallon of gum arabic. This produces a stock solution with a pH value of 2.0-2.5. After 
assessing the drawing, the printer takes a small amount of the stock solution and adjusts the strength by adding more phosphoric acid for a stronger etch or more gum arabic for a weaker etch.

The following etch is used by Myrna Burks, a Tamarind printer currently operating North Light Editions in Portland, Oregon. 10

A stock solution known as TAMPEII is prepared by mixing the following: 42 ounces of MS214, 54 ounces of gum arabic, 22 ounces of Hydro gum, and 1 ounce of phosphoric acid. TAMPEM has a pH value of 2.4. The chart below contains the recommended etch strength for some drawing techniques using the TAMPEM mixture.

\begin{tabular}{l|l|l}
\hline Litho Crayon & Water Tusche & Solvent Tusche \\
\hline \#1, 2, 3, Crayon & Light Tusche & $\begin{array}{l}\text { Light Tusche } \\
\text { 1/2 TAMPEM }\end{array}$ \\
1/2 Gum Arabic & 3/4 GuM AramPEM \\
\#4,5 Crayon & Medium Tusche & Medium Tusche $1 / 4$ \\
TAMPEM & pH 2.3-2.5 & pH 2.1-2.2 \\
3/4 Gum Arabic & Heavy Tusche & Heavy Tusche \\
& PH 1.7-1.9 & 1.2 \\
\hline
\end{tabular}

Fig. 39. Etching chart for TAMPEM etch 


\section{APPENDIX C}

\section{LACQUER PRINTING BASES}

When an extremely large edition of prints is desired, a lacquer printing base may be needed in addition to the regular asphaltum base. A lacquer base provides a very durable and protective mask over the image area. It is particularly effective on delicate tonal areas that can be damaged by the constant friction involved in wetting, inking, and printing.

Three common lacquer bases used in 1ithography are Titan Vinyl Lacquer, Lacquer $C$, and Deep V Lacquer. These products are available from most lithography suppliers. "Some of the contents of these lacquer are highly toxic and must be handled with caution. The aromatic hydrocarbon used... is a primary skin irritant . . as well as a central nervous system depressant." 11 Teachers should be aware of the potential hazards connected with lacquer bases and provide proper ventilation and skin protection if the product is used.

Some printmakers prefer to use a lacquer base during the first etch prior to rubbing up the image with asphaltum. Others prefer to apply the lacquer after the second etch and some printers recommend proofing the plate before using a lacquer base. Once the image has been lacquered, it is impervious to the etch and no adjustments can be made without first removing the lacquer. 
When the decision is made to apply a lacquer base, the plate must first be protected with a thin gum mask. The image is washed out with turpentine or lithotine as usual. Then the image is washed out with lacquer thinner until all traces of ink or drawing pigment are removed. A small amount of the lacquer base is poured on the plate and rubbed gently into the image. The lacquer should be buffed to a smooth film and allowed to dry thoroughly. Asphaltum is applied over the lacquer in the usual manner. The gum mask is removed with a sponge and water and the plate is rolled up and printed as usual. 